\title{
SURGERY OF PERIPHERAL NERVE INJURY
}

\author{
By \\ IAN AIRD, CH.M., F.R.C.S.(ED.) \\ (From the Department of Surgery, University of Edinburgh.) \\ Professor of Surgery Elect, Post-Graduate Medical School, Hammersmith.
}

\section{Introduction}

Peripheral nerves may be injured by open wounds (by bullets or other projectiles or by sharp weapons) or they may occur without skin injury. The closed injuries of the peripheral nerves may be due to sudden direct violence, as in the case of contusion of the external popliteal nerve against the neck of the fibula, compression of the radial nerve by tourniquet, and damage to a nerve by pressure from an operating table, from a crutch, or from the arm of a chair; or they may be produced by injuries of a stretching kind, as in tearing of the external popliteal nerve in forcible abduction of the knee or tearing of the roots of the brachial plexus in a birth injury. They may also complicate fracture or be produced by long-term irritation, as in the ulnar neuritis due to a valgus deformity at the elbow, the paralysis of the lowest fibres of the brachial plexus due to pressure by a cervical rib, and the paralysis of the dorsal interosseous nerve by fascial pressure at the elbow.

Recently, interest has focussed on nerve injuries complicating war wounds, and experience of these has extended substantially knowledge of the processes of nerve. injury and nerve repair. The phenomena of nerve regeneration after injury are much better understood now than formerly, and details of diagnosis and of operative technique have been improved. Even so, it would not be unfair to say that operative technique has made no fundamental advance during the recent war. Our clinical knowledge of nerve injuries has increased by inconsiderable accretions scattered over the whole clinical field, and it would seem profitable to review this against the whole background of our knowledge of peripheral nerve injuries.

The most important principle of the care of peripheral nerve injuries in the second world war was that of the isolation of patients in specialised centres, where the surgeon can co-operate not only with the orthopaedic expert, the neurologist, and the radiologist, but with the physiologist, the pathologist, the bacteriologist, the psychiatrist, and the expert in physical medicine. The patients require repeated study by this team of specialists, and constant opportunity for physio-therapy and occupational therapy, before their final return to industry. Even after surgical treatment ends, long-term follow-up is essential, and opportunities for vocational training and guidance in choice of a career are not the least important duties of the community to men and women who have sustained peripheral nerve injuries.

\section{The Clinical Effects of Nerve Injury}

Nerve injury may produce disturbances of motor, sensory, sudomotor, vasomotor, nutritional, and reflex function in the territory of the affected nerve.

\section{(a) Motor Effects}

\section{Loss of voluntary contraction}

When a nerve is completely divided, the muscles supplied by it are denervated, and no longer contract under volition. The paralysis of the muscles supplied by the injured nerve may, however, be obscured by tricks, synergia, and the employment of subsidiary muscles, and by anomalies of innervation. Notable examples of trick movement are: abduction of the fingers by the extensor muscles in ulnar palsy; flexion of the knee by gracilis in sciatic palsy; extension of the thumb by abductor pollicis brevis in radial paralysis; extension of the interphalangeal joints by the interossei and lumbricals, and adduction of the fingers by their flexors in ulnar paralysis. Notable examples of the use of subsidiary muscles are: flexion at the elbow by the flexors of the forearm when biceps and brachialis are paralysed, and flexion of the wrist by abductor pollicis longus in combined median and ulnar palsy. An example of the trick effect of synergia is the extension of the wrist which may occur when a fist is made, even in complete extensor paralysis (Fig. I).

Anomalous innervation of muscles is another cause of failure to realise the completeness of a lesion, as when thenar muscles with anomalous innervation continue to contract voluntarily after division of the median nerve. Highet's procaine 
block method 48 is invaluable for the detection of skilful trick movements, and of anomalous innervation. A muscle which continues to act after procaine block of the neighbouring uninjured nerve suspected of innervating it anomalously, may be presumed to be innervated by undivided fibres of the injured nerve under study.

A further difficulty in estimating the extent of motor loss in a war injury arises in cases of multiple wounds of an extremity. If, in addition to a wound of a peripheral nerve, muscles are widely damaged or tendons divided, the share of responsibility to be allotted to nerve damage on the one hand, muscle or tendon loss on the other, may sometimes be apportioned only with great difficulty. The visible and palpable contraction of a muscle belly should be studied independently of its kinetic effect.

\section{Atrophy}

A few months after injury the motor end-plates disappear, and, as paralysis continues, the paralysed muscles atrophy; their fibres shrink, lose their cross-striation, and ultimately disappear, to be completely replaced by fibro-fatty tissue sometimes as early as three years after injury, but, as Young has shown in a case of Learmonth's ${ }^{\mathrm{r} 33}$, sometimes as late as 26 years.

\section{Faradism}

Certain electrical changes 8 occur in the denervated muscle. The simplest and the oldest method of studying the electrical behaviour of a muscle is to determine its response to faradism. A normal muscle responds to faradism by contraction, and responds also, but less readily, to galvanism. The contraction produced by application of the cathode to the point of entry (motor point) of the nerve of supply to a muscle is normally greater than the contraction produced by the anode applied to the same point (K.C.C. > A.C.C.). One or two weeks after nerve injury, the nerve and muscle cease to respond to faradism, but for ten days thereafter galvanism continues to give a normal response before it becomes sluggish, vermicular and lingering. In this period an increasingly strong current is required to produce contraction, and the A.C.C. may equal or be greater than the K.C.C. (polar reversal). These changes in the electrical response of a denervated muscle are together known as the Reaction of Degeneration (R.D.). The most significant change is the failure to contract to faradism, and the least significant is polar reversal. The R.D. is said to be complete when faradism no longer elicits contraction, and when polar reversal has occurred; it is said to be partial when faradism is present, but when a stronger current is required than that required for the neighbouring muscle of the opposite side. A curious electrical reaction,, 0 the "paradoxical electrical reaction of ERB," is sometimes seen if a nerve has been compressed for $z$ a time: faradic excitation may be induced in a $\frac{\widehat{\Phi}}{\stackrel{2}{2}}$ segment distal to a lesion which blocks conduc- $c$. tion; stimulation above the block fails to elicit contraction, while stimulation below the block is effective.

\section{Chronaximetry}

The chronaxie of a muscle also alters after nerve division, increasing as the muscle degenerates. Thew chronaxie is the minimum time required to produce $\vec{\circ}$ a contraction by a voltage equal to twice that required to produce a minimal response. In short, $\vec{\omega}$ the chronaxie is twice the rheobase. Muscles varyo in chronaxie from 0.08 to 0.7 milliseconds, but the $\frac{0}{7}$ chronaxie is constant for muscles co-operating in a given movement. Chronaximetry ${ }^{8}$ has been em- $N$ ployed to decide whether the fibres of nerve testediv are intact or degenerated, and it has some signi- $-\overrightarrow{\text { }}$ ficance in this respect, but its value is limited sinceN the method is exact only if all the fibres of the ${ }_{0}^{\mathrm{r}}$

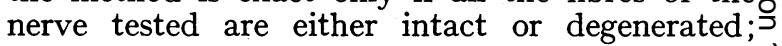
normal fibres are not detected if mixed with de- $\vec{c}$ generated fibres. ${ }^{8}$ Shapiroroo records a lengthen-䨌 ing of chronaxie in the antagonists of the dener- $\frac{\vec{\Phi}}{\mathbb{D}}$ vated muscles.

\section{Electro-myography}

Much more valuable than chronaximetry 성ㅎํ electro-myography. Adrian ${ }^{2}$ first recorded the spontaneous electrical activity of muscles measured by electrodes placed on the skin over them or inserted directly into them, and the method haso been employed by Denny-Brown and Penny-命 backer ${ }^{22}$ and others.45 For some time after injury, voluntary muscle is electrically inactive; that is, $\overrightarrow{0}$ no action currents can be detected when a concen- 3 tric needle electrode connected with a cathode ray镸 oscilloscope is inserted into the muscle. ${ }^{\mathrm{I2}}$ (A galvanic current may be sent down to the needle-O을 electrode after its insertion to determine in which . muscle it lies.) Twelve to twenty-eight days later, $\overline{3}$ fibrillation makes its appearance-irregular fine. spikes of change in potential, totally unrelated to약 attempted voluntary contraction; these variations in potential persist for as long as any contractiles tissue remains, or until reinnervation occurs? Even if spontaneous fibrillation is lacking in a denervated muscle, it may be induced by heat.

With the onset of fibrillation, the denervated muscle becomes increasingly sensitive to acetyl- 0 choline, and Denny-Brown and Pennybacker ${ }^{22} \tilde{C}$ have suggested that fibrillations might be due to circulating acetyl-choline. Eccles 25 found, how 60 ever, that curare lessened the sensitivity of dener-क 
vated muscle to acetyl-choline without affecting fibrillation.

Langley believed that the fatigue of fibrillation was responsible for the atrophy of denervated muscle, but Solandt and Magladery ${ }^{102}$ abolished fibrillation by quinine and quinidine, without preventing atrophy.

Fibrillation ceases in denervated muscle with the disappearance of cross-striation, and the loss of contractility.

\section{Strength-duration curve}

Ritchie $^{8 i}$ has for preference employed the strength-duration curve for the study of the innervation of muscle. A high strength of current is employed for an exceedingly short duration and the voltage is plotted against the duration of the current. The resultant curve is the strengthduration curve. The height of the curve varies from time to time in normal muscle, but the shape of the curve remains fairly constant. Denervated muscle gives a rapidly rising curve, entirely different from that given by normal muscle, and the form approaches normal again as reinnervation proceeds. In electro-myography and in Ritchie's strength-duration curve method, a single observation gives little valuable information, but repeated observations showing a progressive change in electrical activity sometimes allow conclusions to be drawn from them.

\section{Muscle biopsy}

Muscle biopsy is of clinical value in furnishing information of the histological state of denervated and/or ischaemic muscle. ${ }^{\mathrm{II},} \mathrm{x} 3 \mathrm{14}$ Further, since nerve fibres are found in more than nine-tenths of the muscle sections studied, muscle biopsy is a form of nerve biopsy. ${ }^{14}$ Soon after denervation the pattern of muscle fibres becomes more open; the nuclei appear to increase in number and to be grouped together in clumps; and the cross-striation begins to fade. The Schwann tubes, empty of their axons, can still be traced to the motor endplates, which usually remain distinguishable for about nine months after injury.

\section{(b) Sensory Effects}

\section{Anaesthesia}

Immediately after nerve division, there is loss to light touch over a well-defined area, loss to pinprick over a smaller and less well-defined area, and loss of pressure sensibility. Sensory no less than motor distribution of any given nerve varies from patient to patient (Figs. 2 and 3 ), and may even differ on the two sides of the same individual. This is due sometimes to partial replacement of one nerve by another, sometimes to anastomosis be- tween two nerve trunks. Anomalies of sensory, like those of motor, distribution may be detected by Highet's procaine method. $4^{8}$ The clinical measurement of sensory loss is less exact than the estimate of loss of motor function. 85 Pure touch is difficult to produce, for even von Frey's hairs, algometers, and copper rods maintained at a constant temperature produce some deformity of the skin. ${ }^{85}$ Bishop $^{\text {Io }}$ described an electrical apparatus which will stimulate single sensory spots on the skin by high-voltage low-current spark discharge, but his is regarded as a laboratory rather than a clinical method.

Each primary modality of sensation-pain, touch, cold, warmth, and pressure-is subserved by a sensory receptor which is specific for that modality and each receptor is connected with a specific size of myelinated fibre together with an accessory unmyelinated fibre which acts as a sort of "burglar alarm" by evoking the sensation of pain when the stimulus reaches a level which may be harmful to the organism. ${ }^{20}$ In clinical examination of a peripheral nerve injury each modality should be separately studied, and its area of loss mapped out. The areas of total loss of the various modalities differ, their outlines forming concentric rings except in lesions of the brachial plexus. Pain loss, for example, is less than touch loss in lesions of nerve trunks, but greater in root lesions. Cold is intermediate, and warmth is the largest of all. The area of sensory loss varies with the nerve and with the lesion, but large and small areas of anaesthesia may be found after both high and low division of a nerve. 85

\section{Pain}

Pain referred to the area of cutaneous distribution of a damaged nerve is much more common in partial than in complete lesions; in the latter it seldom persists for more than three weeks. It may be of any degree-trifling discomfort, minor causalgia (often referable to fracture, foreign body, soft tissue damage, or wound infection) or true causalgia.

\section{Overlap of dermatomes}

After division of a peripheral nerve some recovery of sensation occurs even without regeneration, as a manifestation of the normal overlap of dermatomes. ${ }^{80}$ Each nerve has an autonomous area whose sensation it wholly and exclusively subserves, but around the autonomous area is an intermediate zone in which sensory function is shared with the nerve of the adjacent territory. Immediately after a nerve injury, this intermediate zone may be or appear to be anaesthetised, but after a few days nerve fibres from adjacent nerves may take over the sensory function of the inter- 
mediate zone, and the area of sensory loss may appear to shrink. Iater still, and up to a time limit of about fourteen days, new fibres from adjacent nerves seem actually to grow into the autonomous from the intermediate zone, $81,85,103$, 123 and the area of sensory loss shrinks still further. This is probably a manifestation of the continuous degeneration and regeneration that takes place normally in the peripheral nerve plexus of the skin. ${ }^{121}$ The ingrowth is slower into the territory of a nerve which has sustained a gunshot wound than into that of a nerve which has been cleanly divided.29 It explains vaunted cases of "complete recovery of sensation" a few days after suture of the median nerve at the wrist-an unusually small median territory having been reinnervated from the intermediate zone around it.

\section{(c) Sudomotor Effects}

While, in partial lesions, sweating is often increased, the hyperhidrosis sometimes extending beyond the area of sensory loss, after a complete injury sweating ceases in the denervated part. Anhidrosis is perhaps the best index, since the most objective index, of denervation of skin. Usually anhidrosis covers a larger area than does anaesthesia.

Several clinical tests have been devised for determining precisely and for recording the area of anhidrosis. Perhaps the most valuable of these is Guttmann's Quinizarin Test.42 The patient is given 5 to Io grains of aspirin and a cup of coffee to induce general perspiration, and the skin of the affected part is then dusted with Guttmann's Powder. This is a mixture of $28 \mathrm{gm}$. of sodium quinizarin 2-6 disulphonate, $24 \mathrm{gm}$. of anhidrous sodium bicarbonate and $48 \mathrm{gm}$. of rice starch (the starch serves as a base and the bicarbonate prevents moistening during storage). The arm is placed beneath a hot-air cradle or in a radiant-heat cnamber, and the powder turns a deep reddishpurple if sweating occurs (Fig. 4). The sweat must not be allowed to run from a perspiring area to an area of anhidrosis. Silverman and Powellior use tincture of ferric chloride diluted with three parts of alcohol, painted on the skin with a cotton-tipped applicator; the skin is allowed to dry and tannic acid powder is then spread over the whole area. Sweating skin blackens first in tiny dots and then diffusely from coalescence of the dots. The black stain can be removed later with five per cent solution of oxalic acid.

Closely linked with the phenomenon of anhidrosis is that of skin resistance to an electric current. Richter and Katz ${ }^{86}$ showed that when sweating is normal skin resistance is low, while anhidrotic skin has a high resistance. If an in- different electrode is attached to the ear and an examining electrode is moved over normal skinn until there is no fluctuation of a connected am- $\frac{2}{z}$ meter, and if the examining electrode is themo moved to a suspected area, the ammeter swings sharply as the skin resistance rises and the area of high resistance can be marked out.56

\section{(d) Vasomotor Effects}

Richards ${ }^{8} 4$ has described in detail the vasomotors changes which occur in denervated skin. They are particularly marked in median, ulnar and sciatien lesions, because in these nerves vasomotor fibresare particularly numerous. The first change is one of vaso-dilatation from paralysis of the vaso $\vec{\omega}$ constrictor fibres, and the denervated skin is redp and warm as it is after sympathectomy. Afteo about three weeks, the skin of the denervated area. becomes blue and cooler, approximates more्d nearly in temperature to its environment, and becomes but little warmer when another part of the body is heated. The second stage, of coon cyanosis, appears to be due to loss of the afferentr limb of the vasomotor reflex ${ }^{84}$, perhaps intensifieof by immobilisation. After a complete lesion of $\mathrm{a}$ peripheral nerve, sympathetic block fails to give क⿱ rise of skin temperature in the affected area.77

\section{(e) Effects upon Reflexes}

Every reflex, superficial or deep, is lost, any of whose arc crosses the point of injury on affected nerve.

\section{(f) Nutritional Changes}

Nutritional changes $4^{6}$ may occur in any tissue supplied by denervated nerve, but they are uno common in any but irritative and painful lesions? The skin loses its pits and wrinkles and become $\overrightarrow{\vec{B}}$ preternaturally smooth, thin, glossy, mottled?̧ translucent and inelastic. Normal resistance to trauma is lost and indolent ulcers develop, especi ally in denervated fingers, toes, sole or heel. There is loss of subcutaneous tissue and the tips of. anaesthetic digits may. shrink and taper. Depila윽 tion is the rule in denervated areas, but increased rate of growth of hair may occur in irrita? tive lesions. The nails become distorted-brittle ridged or curved. Hypertrophic subcutaneous fibrosis is uncommon, but by it the skin may itp irritative lesions be thickened and thrown into. folds, and clubbing of the fingertips has sometimess been observed.

Muscles, as we have seen, atrophy progressivel and ultimately disappear. Muscles and theia tendons shorten and deformities are rendered pero manent by contraction of fasciae and joint capsules also. Contracture and ankylosis of joints develot 
more readily in painful than in painless lesions, and are more common in distal than in proximal nerve injuries. ${ }^{6}$ It is unlikely that these lesions are due solely to immobilisation, for they are selective in their incidence-in tibial nerve lesions the joints of the foot suffer most often, while in common peroneal lesions the ankle is the commonest seat of stiffness. In median injuries the interphalangeal and metacarpo-phalangeal joints suffer, and there is often a partial metacarpo-phalangeal ankylosis of the thumb which permits movement only in the plane of the palm. The risk of contracture and ankylosis increases with age and with virulence or chronicity of associated sepsis. German and Russian authors have theorised lengthily about contractures and explain them as a reflex phenomenon, but their evidence of a reflex effect is not convincing.

The bones may undergo a progressive decalcification which, too, is more rapid and severe in partial and painful lesions. The decalcification is most intense in the proximal and distal extremities of the phalanges, and the radiological appearances resemble those of the post-traumatic osteo-porosis of Sudek. Median nerve lesions, particularly those associated with causalgia, are most apt to produce osteoporosis. The increased blood supply of the bone incidental to the lessened demands of wasting muscle has been blamed for this decalcification, 46 but the voluntary immobility of the causalgic hand certainly aggravates it. It is of interest that osteo-porosis, like causalgia, is more frequent in injuries of the median than in lesions of any other nerve.

\section{The Clinical Signs of Recovery}

\section{(a) Rate of Reinnervation}

When an injured nerve recovers, either spontaneously or as a result of suture, the axon tips proceed in regeneration at fairly standard rates. There is first a latent period of about seven days, followed by a progressive advance of 0.25 millimetres per day through the injured part, and then of 3 or 4 millimetres a day in the distal stump of the nerve; 37 if the nerve has been crushed only and its perineurium has not been divided, the latent period is shorter and the rate of advance is more rapid. Finally the growing axons reach their endplates, and some time passes before connection is established. Meantime, the axons have become medullated centrifugally at a rate which progressively slows as the periphery of the injured nerve is reached. There are thus really three temporal stages in reinnervation: an initial delay of three weeks or more (dependent on the form of interruption) at the lesion, the time of travel down the nerve at the rate of 3 or 4 millimetres a day, and the period between the arrival of the fibres at the structure they innervate and the return of function, and the date of expected recovery in any muscle can be roughly calculated. The wave front of functional maturation as it proceeds down a limb follows not a straight line but a parabola, rapid at first and slow as the distal extremity is reached.98 The distal retardation may be due to the progressive slowing of myelinisation as regeneration proceeds further and further from the parent stump on which it depends, and partly also to the greater degree of atrophy of end organs and of muscles in the more distal parts of a denervated extremity.

\section{(b) Progress of Motor Recovery}

This can be demonstrated in a muscle before $N$ voluntary contraction can be elicited in it, and the introduction of more delicate electric methods during the recent war for the measurement of muscle activity has aimed at detection of reinnervation before actual contraction can be induced. The first sign of reinnervation is a change in the electro-myograph. As long as three months before the appearance of voluntary movement, fibrillation may cease in the reinnervated muscle; large action potential variations are then observed, charac teristic of motor unit activity. ${ }^{12}$ They appear of the screen on attempted voluntary contraction and they are a sign that some return of voluntare power can be expected in due course. No reliancê can be placed on an isolated observation, for the finding of an odd patch of apparent reinnervation means only that a few motor fibres have arrived and does not tell what is happening in the nerve as a whole. Repeated observations at short intervals are therefore necessary.

Three to nine weeks before the first appearance of voluntary power, a change may be observed in the strength-duration curve. 87 This cannot be elicited as early, as a rule, as the change in the electromyograph, but an alteration in the shape of the S.D. curve when it is obtained is perhaps a more reliable index of reinnervation. Here again, at $\delta$ least two observations are required to detect a return to the normal shape of curve.

A few weeks, or perhaps months ${ }^{\mathrm{I}} 4$ before the first clinical signs of recovery, muscle biopsy will show the presence of axons in the Schwann tubes of intramuscular nerve fibres, if regeneration has $\stackrel{\circ}{\circ}$ proceeded so far. If myelination is far advanced, $\tilde{N}$ the nerve fibres of regenerating nerve may differ from normal fibres only in branching more freely and ending at a distance from the end-plates. If no axons are visible when it is reasonable to expect them there must either be a division of the nerve or other serious obstacle to regeneration. ${ }^{14}$ 
Finally, voluntary movement returns with a lowering of chronaxie, and the normal response to faradic stimulation. It is of interest that voluntary contraction can frequently be detected before a faradic response can be obtained, and the use of electrical methods, therefore, in no way absolves the clinician from careful and repeated study of voluntary power in the denervated muscles; muscle testing should be performed at intervals of a week or a fortnight before the earliest date of expected recovery; the patient must be warm, alone with his examiner, fresh, and free from fatigue.

Highet, ${ }^{68}$ for convenience of recording, recognised six stages in the voluntary recovery of muscle:-

(o) No contraction;

(I) Return of perceptible contraction in proximal muscles;

(2) Perceptible contraction in both proximal and distal muscles;

(3) All important proximal and distal muscles act against resistance;

(4) Synergic and isolated movements added to previous recovery, and

(5) Complete recovery.

\section{(c) Progress of Sensory Recovery}

We have already mentioned that sensation may be recovered early in the periphery of the denervated zone by an assumption of function in the intermediate area of two adjacent nerves by fibres from the area served by the undivided neighbour $8 \mathrm{r}$ and that later, up to fourteen days after injury, new nerve fibres may actually grow in to the autonomous zone of the denervated area from the terminal fibres of adjacent nerves. ${ }^{122}$ Later, and pari passu with motor recovery, regeneration occurs by the downgrowth of nerve fibres along the trunk of the injured nerve. In the case of large nerve territories in the extremities, sensory recovery begins proximally and spreads centrifugally, but so far as nerves with a circumscribed proximal distribution such as the axillary are concerned, the zone of sensory loss shrinks concentrically, for axons entering such an area from the main trunk reach it first at its periphery.123 The reinnervation of a whole thickness skin graft proceeds centripetally in the same way.

As sensation returns, it presents three characteristics, which were described by Trotter and Davies 16, 117:-

(I) A higher threshold of stimulation is required to elicit sensation. If constant intensity of stimulation is employed the first signs of recovery may be missed. This accounts for the common observation that pain returns before touch. Pain has normally a variable threshold and pinprick is a variable stimulus, while a wisp of wool is a constant stimulus which may fail to elicit early signs of recovery. If von Frey hairs are used, the intensity of stimulus can be stepped up, and recovery of touch is found to coincide with $\bar{Z}$ recovery of pain, or to follow it very closely. It is $\bar{\Phi}$ interesting to know that the higher threshold of $\varrho$ stimulation required is not due to a lessened conduc- $\subseteq$ tivity of the nerve; the excitability of growing nerve is increased rather than diminished.

(2) Sensation is intensified. The specific sensation, 읃 when it returns, is unusually vivid. This is especi- $\bar{\sigma}$ ally true as regards pain and cold. Touch does not $\overline{\bar{s}}$ lend itself to intensification, and warmth, when $\stackrel{\mathbb{D}}{\vec{D}}$ intensified, tends to be felt as pain.

(3) Sensation is referred peripherally. In the early stages of recovery when only the proximal part of $\overrightarrow{ }$ the denervated area has regained 'sensation, a $\vec{\circ}$ stimulus applied to the denervated part is referred $\vec{i}$ towards or to its distal extremity. If the stimulus $\vec{\omega}$ is painful, the patient may rub the distal part, and $\stackrel{D}{D}$ even, as Richards ${ }^{8}$ has observed, obtain relief from the rubbing. Peripheral reference is easily shown in 3 the case of touch, cold and pain, but is difficult to is elicit with warmth. As recovery proceeds towards $\mathrm{N}$ the distal parts of the denervated area, sensation in may be referred proximally (Trotter and Davies, ${ }^{116}$ ) $G$ even to a point outside the denervated area alto- iv gether, such as the site of nerve suture. Richards $85 \mathrm{~N}$ has further demonstrated that peripheral reference may be accompanied or followed by "cross-reference", in a recovering median lesion, a stimulus applied to the index finger may be referred to $\infty$ the middle finger or the thumb. Intensification $\frac{\mathbb{D}}{0}$ and reference are the most constant and persistent $\frac{\vec{D}}{\mathbb{D}}$ signs of regeneration after suture, and may be present for many years even after acuity has reached a high standard (Richards).

Pain, subserved by undifferentiated nerve encis of the "free-beaded" type, and by relativele primitive fibres (the unmyelinated and finemyelinated types $\mathrm{C}$ and $\mathrm{B}$ of Fulton ${ }^{2}$ ) has always a better chance of sensory recovery than the other modalities, and may be the only form of sensation recovered.

After a nerve injury of the type which has $\stackrel{2}{\overrightarrow{0}}$ left neurilemma and Schwann cell tubes intact, $\frac{0}{3}$ recovery should approach roo per cent, as Schafer $9^{2}$ proved in his own little finger. After nerve section and suture, recovery is always imperfect, for after suture the chances that an 3 . axon reaches its own Schwann-cell tube are remote and the most that can be expected is that the axon will find its way into a tube which will lead it to a 8 receptor similar to that which it innervated previously36; final grades of touch and thermal $\frac{0}{2}$ sensation, accurate localisation and two-point discrimination and stereognosis are never regained. Similarly, Richards found that intensification and reference were seldom elicited unless the Schwann $N$ tubes had been damaged at the point of injury, $N$ and he believes that reference occurs only when N there has been some crossing of axons. ${ }^{85}$ Sperry ${ }^{104} \underset{\sigma}{\sigma}$ by crossing sensory nerves in the experimental animal has shown that localisation cannot be perfectly relearnt.

For reasons which have already been given, 


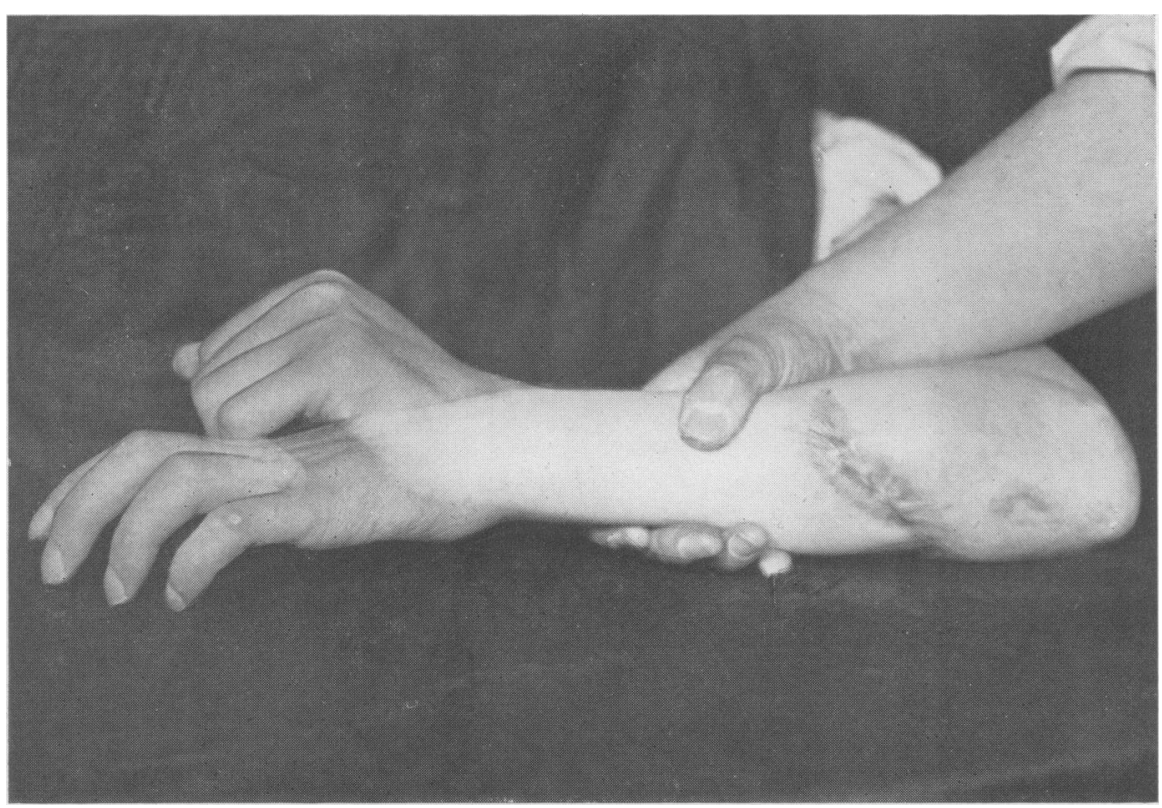

FIG. I.-Dorsiflexion of wrist when fingers are flexed, despite complete extensor paralysis. An example of the trick effect of synergia.

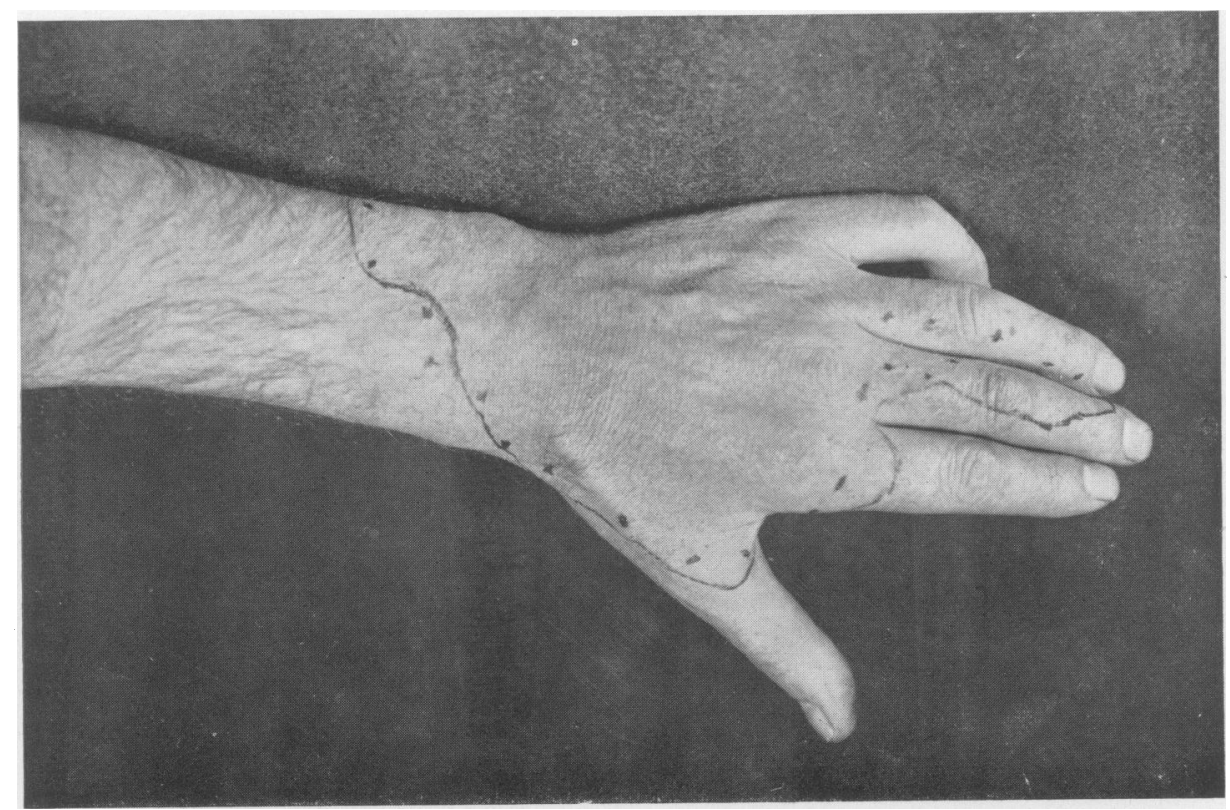

FIG. 2.-Complete ulnar nerve lesion. Dorsum of palm showing unusually large sensory loss. 
Fig. 3.-Complete ulnar nerve lesion. Dorsum and palm showing unusually large sensory loss.

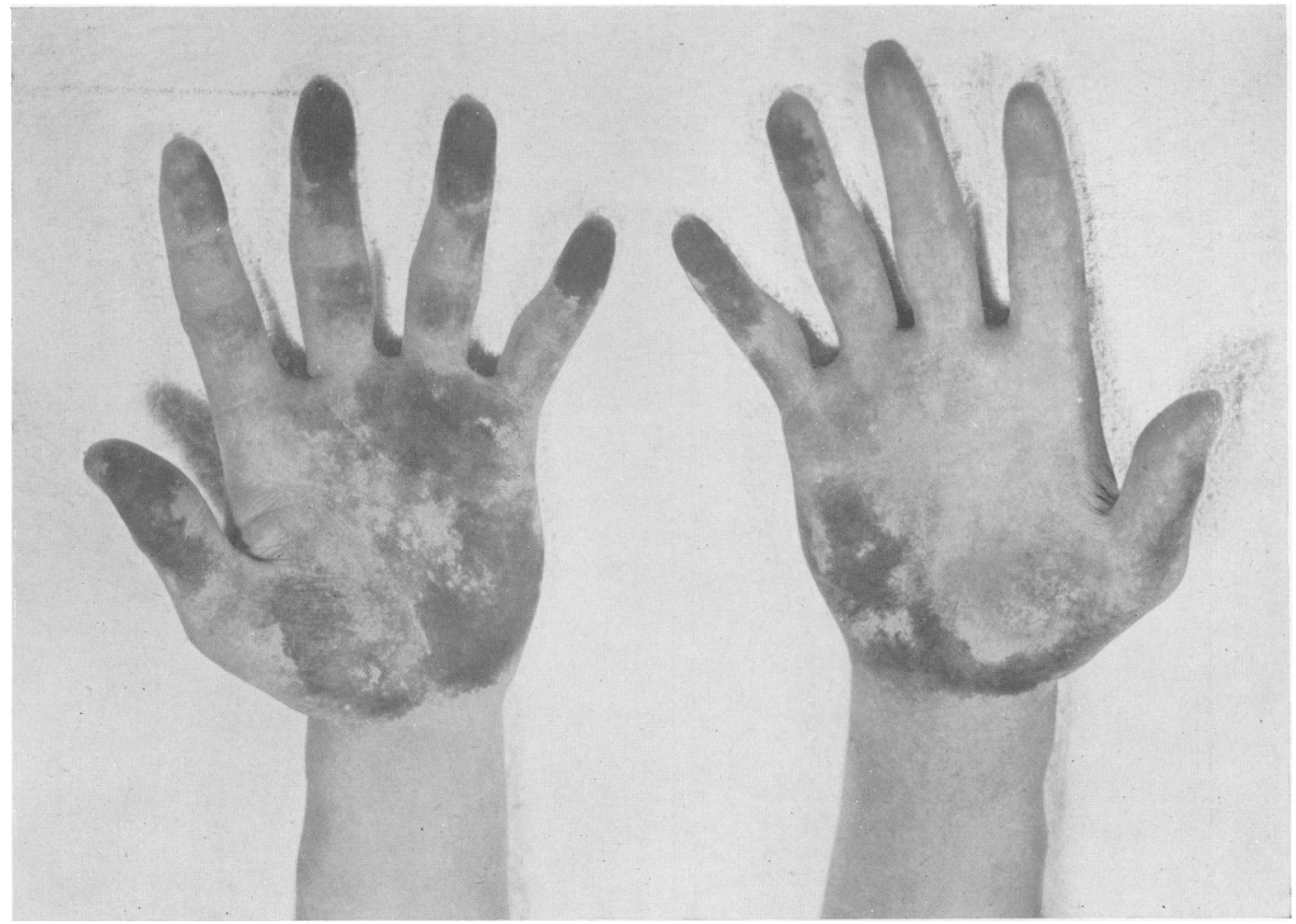

FIg. 4.-Guttman's sweating test. Anhidrosis of right palm in complete median lesion. Note wasting of thenar eminence, and simian position of thumb, which is rotated so that its palmar surface is almost in the same plane as that of the palm of the hand. 
sensory recovery, particularly in the periphery of a denervated area where it marches with an area which has retained normal sensation, is not always good evidence of regeneration, ${ }^{16}$ and there may be a further curious and complicating factor. Nerve fibres, small and usually non-medullated, may grow from blood vessels into the peripheral stumps of nerves for a sufficient length to produce a reflex response to stimulation and to give some sensory effect if the distal trunk of the damaged nerve is stimulated electrically at an operation performed under local anaesthesia. 55

For the recording of sensory recovery Highet 68 suggested five stages:-

(o) Absence of sensibility in autonomous zone;

(I) Recovery of deep cutaneous pain sensibility within the autonomous zone;

(2) Return of some degree of superficial cutaneous pain and touch within the autonomous zone;

(3) Return of superficial cutaneous pain and touch throughout the autonomous zone with the disappearance of intensification;

(4) As for stage (3), plus recovery of two-point discrimination within the autonomous zone.

Tinel's Sign,112, 13 "le Signe du Fourmillement," may conveniently be discussed here. Introduced as a sign of nerve regeneration in I9I7, the distal tingling produced by tapping the injured nerve has now fallen into discredit as evidence of the progress of the growing axon. In many cases, it is true that if the line of a nerve is tapped at different levels until a point is found where a tingling sensation is referred distally from the point of tapping the sign will be elicited progressively more distally along the regenerating nerve. Most workers during the recent war, however, have found again and again that patients with Tinel's phenomenon, even when it was carefully and conclusively elicited by tapping the nerve trunk disto-proximally, were found at operation to have widely separated nerve ends without the slightest possibility of regeneration (Coleman, ${ }^{18}$ Seddon,94 Pollock, 82 and Cairns and Youngi6). Pollock and Davies failed to elicit Tinel's sign in seven of fifty recovering nerves, and they found it entirely absent in only seven out of fifty complete lesions. Even an "advancing Tinel's sign" may be found with complete anatomical division. Of recent writers, Nathan and Rennie74 alone find any merit in Tinel's sign as evidence of regeneration, but even they regard a negative Tinel's sign as of no value, and accept even an advancing sign with some reservation.

TYPES OF NERVE INJURY

Nerve injuries can be conveniently divided into the following six types, based on the classification of Seddon97:-

(I) Complete division (the complete neurotmesis of Seddon), when the nerve is divided across in its whole thickness;

(2) Incomplete division (partial neurotmesis), when the nerve is partly severed, some portion remaining undivided:

(3) Axonotmesis (Seddon), when certain axis cylinders are disrupted within the nerve, without disturbance either of the Schwann tubes or of the neurilemma;

(4) Neurapraxia (Seddon), when nerve function is lost from traumatic demyelination of the larger fibres, without other damage to axons or to their coverings ${ }^{21}$ it may be partial or complete;

(5) Ischaemia of a segment of nerve or of segments of more than one nerve;

(6) Combinations of two or more of the last four of these.

"From a single examination it is absolutely impossible to differentiate a complete division (neurotmesis) from a complete lesion in continuity (axonotmesis or neurapraxia). Moreover, one cannot predict whether the nerve will recover spontaneously or require surgical treatment." (Pollock. ${ }^{8}$ ) Nevertheless, a provisional diagnosis should be attempted when the patient is first seen, with the reservation that it may require correction or modification later.

(I) It is simpler to exclude complete division (complete neurotmesis) from the diagnosis than to assert confidently that it is present. It is not present if some part of the affected nerve's function can be conclusively shown to be present. Conversely, in complete division (complete neurotmesis) there is immediate and total sensory, motor, sudomotor, and vasomotor paralysis over the whole area of the affected nerve, but the same total loss of function attends complete axonotmesis and complete neurapraxia,.and unless the nature of the injury gives some immediate hint these can be differentiated from neurotmesis and from each other only when indications of recovery or degeneration appear with the passage of time. The development of a palpable neuroma in a patient with a total loss of function is strong evidence of complete neurotmesis.

(2) In partial neurotmesis the changes are similar to those of complete neurotmesis, but affect an area less than the whole area of distribution of the affected nerve. Not all muscles innervated by the nerve cease to function, and sensory loss is only partial too, unless, as sometimes happens, all the sensory or all the motor fibres are in the part divided. Sensory disturbance may take the form of a diminution in the intensity of sensation (hypoesthesia) without its complete loss in any one part of the area supplied; this form of sensory loss is commonly seen in traumatic ulnar neuritis. Persistent hyperaesthesia, hyperalgesia, or pain is suggestive of a partial lesion; spontaneous pain is uncommon in. a complete lesion, and, if it occurs, usually disappears after a few weeks. So, too, persistance or excess of sweating in the territory of an injured nerve is indicative of a partial lesion.

In most cases of partial neurotmesis, a hard neuroma develops at the site of trauma, and if this 
is palpable the diagnosis is clear, and operation is indicated. ,

Differentiation of partial from complete neurotmesis is particularly difficult in a sensory nerve with a small territory of supply. Procaine block (Highet) $4^{8}$ has a special application here. If after block of the affected nerve anaesthesia is increased, or if after block of its neighbour or neighbours sensation remains, division may be regarded as incomplete.

(3) and (4) Axonotmesis and neurapraxia can be distinguished from the first two forms of injury by the absence of a palpable neuroma, and also by dissociation of sensation, if it occurs. In neurapraxia subjective numbness, paraesthesiae, and some loss of position sense may occur without objective sensory loss; the fibres for position sense are among those large calibre fibres whose myelin sheaths seem particularly sensitive to concussion. In general, however, only the passage of time differentiates neurapraxia from axonotmesis. In the former, fibrillation does not appear in the electro-myograph, the strength, duration curve remains of constant shape, the reaction of degeneration is still absent after three weeks, for Wallerian degeneration does not occur, muscle biopsy (occasionally justifiable in this connection if a suspected neurapraxia is slow of recovery) shows a normal histological picture, and recovery is early and quickly complete.

Attempts have been made by contrast radiography to show whether interruption in a nerve's continuity is complete. ${ }^{88}, 107$ Perabrodil in saline may be injected intraneurally; if it passes the site of injury, conduction is likely to be recovered, and the injury may be assumed to be either neurapraxia or axonotmesis; if the perabrodil fails to pass the site of injury, it is doubtful whether recovery will occur. The method is technically difficult, and not without risk of injury to the nerve investigated, and it is unlikely to become generally popular.

(5) The presence of ischaemia in a nerve or in the muscles which it supplies may easily be overlooked. Pronounced contractures and loss of voluntary power in muscles other than those supplied by the injured nerve are strongly suggestive of the presence of ischaemia, particularly if any sensory disturbance follows a glove or stocking pattern rather than the pattern of an area supplied by the injured nerve trunk. The possibility of ischaemia of a nerve or of the muscles supplied by it should be considered particularly if one of the main arteries is known to have been damaged or if the distal pulses are impalpable; ischaemic effects are greatest when, in addition to damage to the main arterial trunk, collaterals are divided in an extensive wound. The presence of ischaemia renders recovery unlikely even after an apparently successful suture, and the frozen, contracted atrophic, and discoloured appearance of this doubly affected extremity is a danger signa $b$ warning against any attempt at nerve repair. Ifthere is any doubt about the degree of ischaemia in one of the muscles supplied by an injured nerve $\frac{\text { ? }}{t}$ muscle biopsy should be performed. II The histological changes of ischaemia are characteristic even when associated with those of denervation, anfo timely biopsy may avoid an operation doomed to failure and the deferred hope of a fruitless con valescence. II

A neurological defect associated with a traumatic aneurysm usually appears full-blown at the time of injury, 27 and rarely recovers spontaneously; if exploration is delayed for a month or two to allowe full expansion of collaterals, nerve and artery car. be dealt with simultaneously.

Ischaemia of nerves and of their territoriesi occurs, of course, in thermal lesions of the extremities, and it occurs too in damage to the main vessels of a limb, but a more insidious type of nerver ischaemia has been described by Parkes76 and by Seddon and Holmes.99 The latter authors describe a median nerve injury with all the manifesta $\infty$ tions of median nerve interruption, with a division of the nerve and a neuroma on its proximal stump in the upper third of the forearm. They found however, that the distal segment of the nere appeared at operation to be threadlike from level of the lesion as far as the wrist, and his logical examination showed an excessive amounfo of collagen in each funiculus, almost entirelys limited to the endoneurium. The nerve alone had suffered, and the muscles were not ischaemic, anch Seddon and Holmes concluded that the change in the distal segment was probably due to a con $\Rightarrow$ comitant occlusion of the anterior interosseus artery and its median branch. Parkes recorded as similar type of lesion in both upper and lowest. limbs. Paralysis in nerve trunks occurred withouf nervous interruption demonstrable at operation In the upper limb cases, the main vessel was. generally damaged, but in the lower limb the cause $e^{\text {. }}$. was usually a closed fracture with great swelling of the leg followed by numbness in the foot, the muscles and nerves suffering ischaemia fromo pressure. Nerve fibres do not all resist ischaemia equally, and often there is a delay in the onset on the nerve disability; the unmyelinated $\mathrm{C}$ fibres. subserving slow pain are the most resistant to asphyxia.

(6) Combined lesions offer great difficulty in differential diagnosis. Only the passage of time $e_{\sigma}^{\omega}$ repeated and careful study, and a detailed clinicat record will permt the assessment of a combineef injury in termsi of partial neurotmesis, partias axonotmesis, partial neurapraxia and ischaemia 
The co-existence of all four of these is admittedly rare-when a missile passes through a main artery and its companion nerve, dividing certain of its fibres, disrupting the axons of others, and breaking in others again the continuity of their myelin sheaths-but a combination of neurapraxia and axonotmesis, or of neurotmesis and axonotmesis is not uncommon.

Even more puzzling are instances of double division of a nerve, or different forms of nerve lesion at different levels, or the occurrence of paralysis from sulphonamide or serum injection, or of pressure paralysis, or of unrelated nontraumatic nervous disease, in a wounded limb. All these demand accurate records for their confident elucidation.

\section{Level of Injury}

When the type of lesion has been established, its level must be decided from the site of injury and from the extent of anaesthesia and of paralysis. In nerve injuries associated with fracture, the level of the fracture, and consequently presumably of the nerve injury, is known. Considerable difficulty in ascertaining the level of the lesion may be met if a patient has sustained multiple wounds. It may be difficult to decide, for example, at what level in axilla or arm the ulnar nerve has been damaged, and a wide exploration may be necessary if operation is performed. If a neuroma is palpated or if a foreign body is seen radiologically near the track of the nerve, a strong suspicion of the level may be entertained.

Even more treacherous are the circumstances when a nerve injury occurs at two or more separate levels. The ulnar nerve, for example, may be doubly divided in a gunshot wound of the flexed elbow, and a nerve injury may occur in a lower limb and escape notice because of a concomitant cord lesion. In the latter case, physical examination will often prove the double injury.65 The presence of a scar may raise the suspicion of a pressure palsy below the higher lesion. Continued paralysis of one muscle group, when other muscle groups have recovered, should again suggest a double lesion. Disproportionate wasting of a lower limb after a spinal injury should attract attention to a concomitant peripheral nerve lesion, as also should the failure to elicit a mass reflex by stimulation within the cutaneous distribution of a peripheral nerve. If the nerve lesion is in the cord only, no fibrillation action potentials are registered in the myograph; evidence of fibrillation suggests a complicating peripheral nerve injury. In an injury of the cauda equina complicated by a peripheral nerve lesion below, fibrillation is present in muscles supplied by the injured nerve, but there is no anhidrosis in its cutaneous territory.

\section{Treatment}

\section{(a) Immediate Treatment}

In a wounded man who has sustained a peripheral nerve injury at the time of wounding, the first aim is to save life and to treat the main wound. During the surgical débridement of the wound, a nerve may be found divided in it. No formal suture should be performed. The nerve ends may be approximated to each other by two non-absorbable sutures or, if they cannot be so approximated, a suture should be placed in the divided perineurium at each end, so that the nerve can subsequently be found readily, or the divided ends may be sutured to adjacent muscle or fascia to prevent their retraction. Care should be taken to avoid the application of any large quantity of sulphonamide directly to the injured nerve. Sulphonamide in small doses, such as are given when a wound is lightly dusted with powder, probably does not damage a nerve, but nervous tissue is extremely susceptible to large local concentrations of sulphonamide, and paralysis may follow the application of sulphonamide to the surface of an undivided nerve trunk.54 Primary or secondary suture of the skin wound should be performed without regard to the nerve injury. During evacuation and early convalescence the limb should be splinted, not only to afford immobilisation to wounded bone and soft tissues, but also to ensure relaxation of paralysed muscle and the avoidance of pressure on anaesthetised skin. More, perhaps, than any other injury, the nerve injuries of warfare require careful documentation, for on the clinical record may depend future successful operation. It is important to record the date and time of injury, the nature of the trauma, the presence of associated injuries (particularly to vessels, muscles and tendons), the site of entrance and exit wounds, the position of the limb when the wound was sustained, the type of local or radiating pain, numbness and weakness after wounding, the appearance of the wound at operation, the colour and temperatures of affected and unaffected limbs and the presence of pulses, the presence or absence of sweating, whether a tourniquet has been used and for how long, and the precise operative procedure undertaken.

\section{(b) Definitive Treatment}

\section{Whether to operate}

Neurotmesis, partial or complete, must be explored. Axonotmesis, if not associated with neurotmesis, requires exploration only if regeneration is prevented by dense perineural scarring. Neurapraxia, unaccompanied by any other type of lesion, should not be explored. 
The clearest indications for operation are: (I) a nerve already seen divided at a débridement operation, and (2) a tender swelling on the course of a nerve, at the site of an injury, and associated with motor or sensory loss in the distribution of that nerve; a palpable neuroma is certain evidence of complete or partial neurotmesis.

If there is no neuroma palpable, the decision to explore is postponed. Successive opportunities arise for reassessment of the developing situation. A neuroma may become palpable on the one hand or, on the other, signs of recovery may appear. The appearance of the reaction of degeneration is not in itself an indication for operation, and an advancing Tinel's sign is not an indication against it. For each affected muscle the expected time of recovery can be estimated, and failure of signs of reinnervation in electro-myograph or strengthduration curve when these signs might reasonably be expected is good reason for exploration.

In deciding whether or not a lesion is a neurotmesis requiring operation, or an axonotmesis which will recover without operation, consideration must be paid to the individual nerve. In the case of injury of the ulnar nerve just above the elbow there is not long to wait before signs of re-innervation appear in the flexor carpi ulnaris, and little is lost by waiting; in injury of the sciatic nerve in the buttock it may be many months before signs of recovery in the calf muscles, and the optimum time for operation may be missed by procrastination.

Even if some recovery occurs, difficulty may arise in deciding whether to operate if that recovery ceases short of complete function. The contribution of the nerve injured to the total function of the limb must be considered. There is little point in exploring a median or posterior tibial nerve whose sensory function has largely recovered, or an ulnar nerve whose motor function has returned; yet a median nerve which has regained only motor function, or an ulnar which has regained only sensation, may well merit exploration and perhaps resection and suture.

Learmonth ${ }^{60}$ has advanced certain indications for exploring an injured nerve irrespective of evidence of regeneration, with the object of ascertaining its exact condition and ensuring a good permanent bed. These indications include previous long-continued sepsis in the wound; the situation of the injured nerve at the bottom of a healed "trough" wound (this is particularly common in the case of the ulnar behind the elbow); a history of unusually severe bleeding from a muscle mass at the time of injury which may have resulted in local necrosis of muscle and late strangulation of such a nerve as the median under pronator teres; closed injuries of the crushing type when such a nerve as the sciatic is likely to be tightly gripped in a collar of fibrous $\overrightarrow{0}$ tissue formed from bruised hamstrings; concomitant $气$ injury of the main artery at the same level as $\frac{3}{\infty}$ the nerve; injury of more than one nerve of a limb at the same time; and, lastly, persistent pain $\leftarrow$ or persistent hyperhidrosis in the area of distribu- $\overrightarrow{\vec{m}}$ tion.

To some extent, too, the decision to operate $\frac{\text { 응 }}{5}$ depends upon the degree of success which is known $\frac{\bar{\sigma}}{\overline{0}}$. to attend suture of the particular nerve injured. $\vec{\nabla}$ In a complete lesion of the dorsal interosseous $\varrho$ nerve the results of suture are in general so un-ळ satisfactory that there is justification for the view $\overrightarrow{0}$ that no useful purpose is served by performing it; $\overrightarrow{ }$ even so, exploration may confirm that the lesion is $\vec{\omega}$ neurotmesis and that tendon transplantation may? proceed at once. So, too, in a high complete lesion $\frac{0}{3}$ of the brachial plexus operation offers no advan tage.

\section{When to Operate}

When it has been decided to operate, the time N for operation must be chosen. In a closed lesion, 0 the most suitable time for intervention is probably in the third or fourth week after the injury has $\vec{\infty}$ been sustained. Since the ability of the central $\mathbb{D}$ stump to send forth axons is not impaired if it be $\underset{\mathbb{D}}{\vec{D}}$ severed a second time more than a week and less 3 than a year after its first division, 55 there is n్ advantage in immediate suture, and there may some disadvantage in it. In the third or four week, the outgrowth of Schwann cells from the distal stump is at its most vigorous,, 55 and on this outgrowth of Schwann cells, attracted 73 or at least accelerated ${ }^{1}{ }^{1}$ towards the proximal stump by a kind of reversed neurotropism, but proceeding throughout the whole distal segment as far as the $\mathbb{Q}$ myoneural junction, depends probably the number $\overrightarrow{\overrightarrow{0}}$ of outgrowing axons which will find a path to the 3 periphery. At this time also, the slender perineurium is toughened by fibrosis and lends itselfo to successful suture. A delay of one or two months $-\overrightarrow{0}$ probably does not hinder the operation greatly, for 3 . regeneration is no slower after excision of neuroma and suture than after primary suture, 55 but a delay 3 . of longer than five or six months will delay finalo reinnervation and will lessen the degree of ultimate functional recovery. After about one hundred dayso from the time of injury, the whole peripheral $\rightarrow$ stump shrinks, and the Schwann tubes narrow, 55 으․ while the endoneurium and perineurium become thickened by collagen, so that there is incongruityo of size at the suture line; relatively few growing 0 axons find Schwann tubes for their passage; the స్ల ultimate size of the growing fibres remains small;o medullation is slow, and final functional recovery is inferior in quality. Moreover, as time passes, the gap between nerve ends may increase, and the 


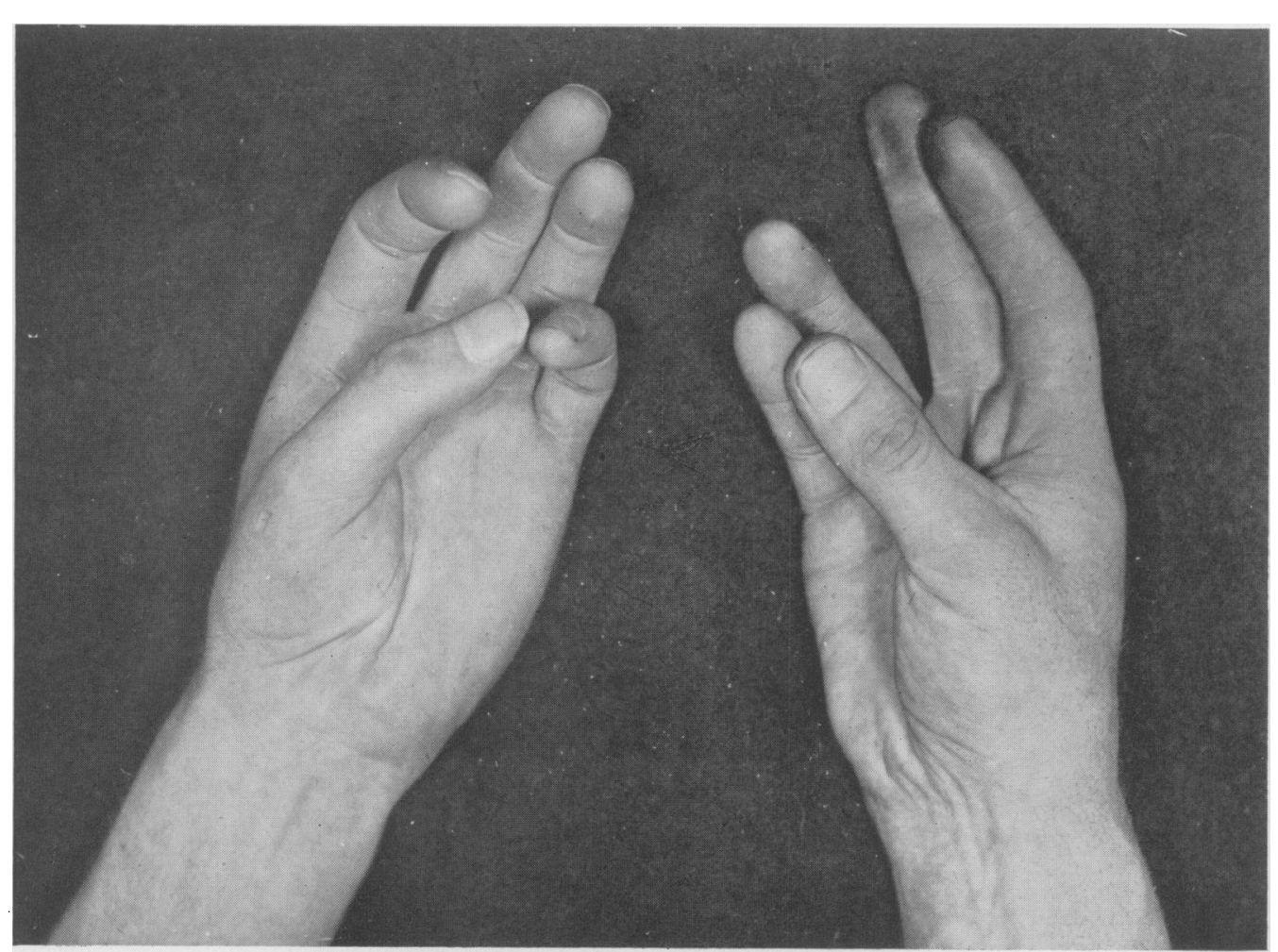

FIg. 5.-Median paralysis. Failure of opposition of right thumb. Note wasting of thenar eninence.

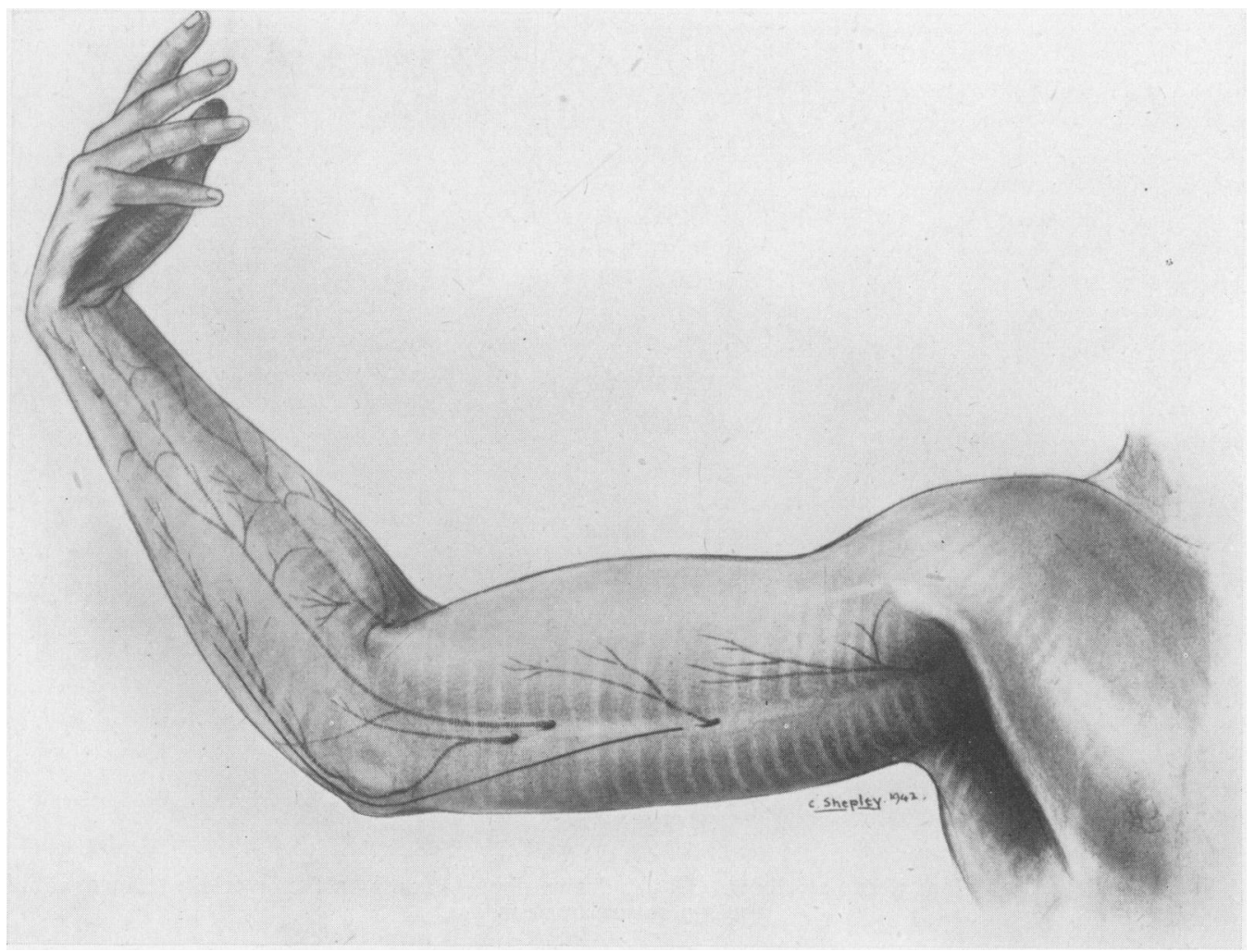

FIG. 6.-Repair of ulnar nerve at elbow. Incision. (After Learmonth.) 


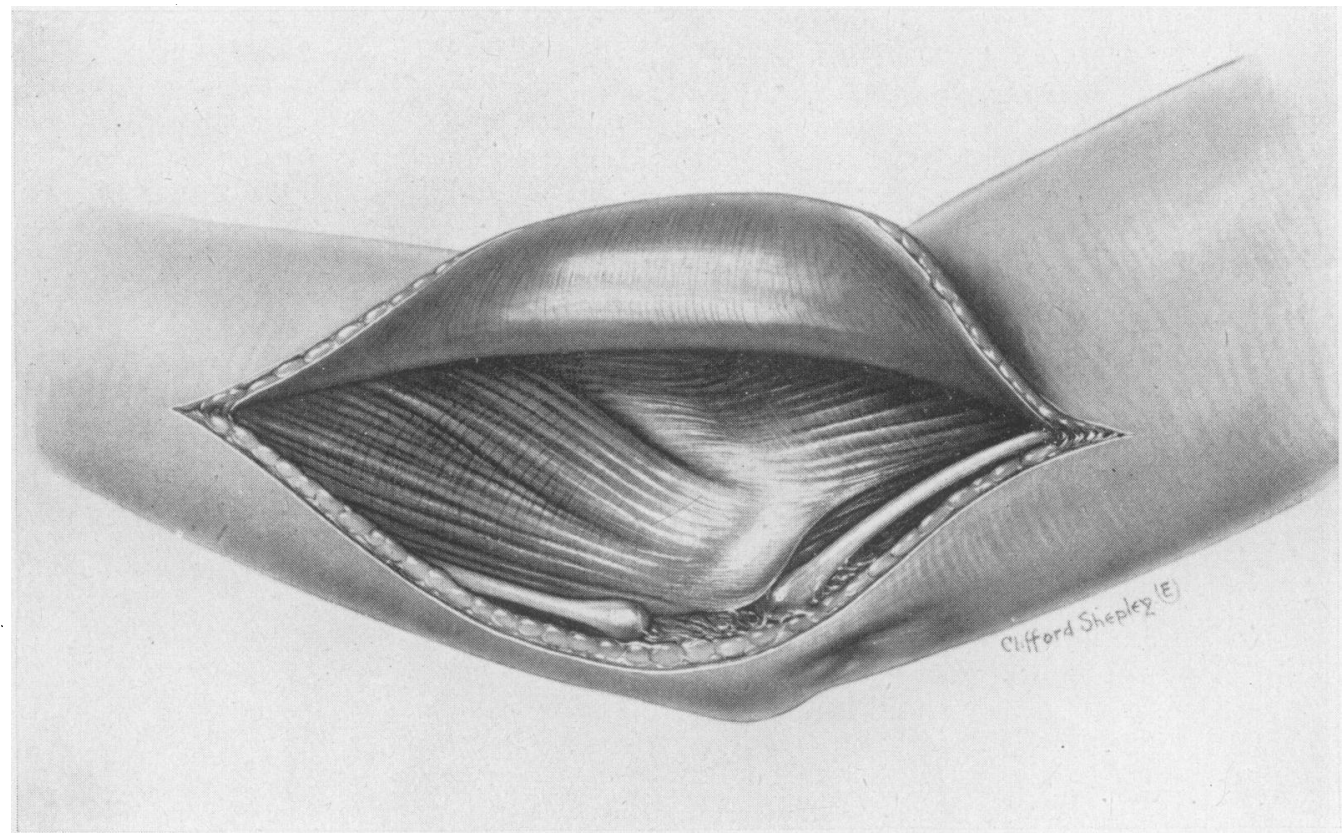

Fig. 7.-Repair of ulnar nerve at elbow. Neuroma and glioma exposed and cleared.

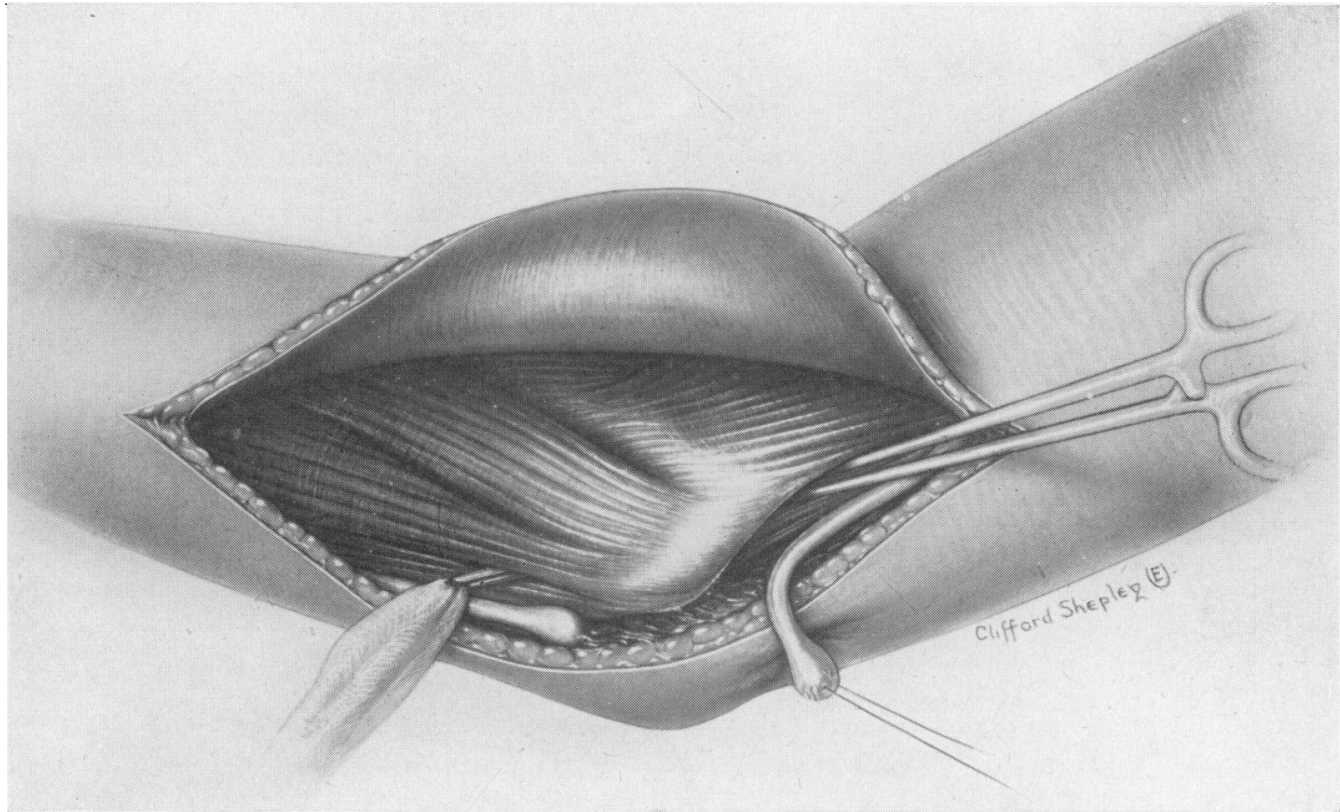

FIg. 8.- Repair of ulnar nerve at elbow. Gauze drawn deep to common flexor origin to form canal; traction suture in neuroma. 
proximal and distal stumps may become less elastic and extensible. Spurlingros has shown that in American wounded who sustained nerve injuries in the European theatre of war, when operation was performed between the twenty-first and twentyeighth days only I per cent of the patients had gaps too great to be closed by suture; after the North African Campaign, when nerve injuries were evacuated to the United States, Io per cent of the gaps were too great to be closed by suture.

German surgeons in general waited some months before undertaking operation,53, 114, I15 apparently because they confused neurapraxias with other forms of nerve lesion, ${ }^{2} 24$ and they waited in the hope that each individual lesion would turn out to be a neurapraxia. The Italians, on the other hand, operated on the eighth to tenth day after injury 23 if there was complete paralysis of a large area, and if electrical reactions had already changed.

Operation should not, of course, be undertaken in the presence of an unhealed wound, or, indeed, for about fourteen days after healing; a healed wound should be massaged daily before operation to make sure that infection will not reawaken in it. Since the advent of penicillin and the increased popularity of delayed and early secondary suture, the average time of operation upon nerve injuries has become substantially earlier.75 Learmonth and Wallace ${ }^{6} 3$ have shown how useful in this respect is a close collaboration between plastic and peripheral nerve units. Not only can open wounds be closed by plastic methods, but dense scars can be replaced by whole skin and fat, so that scarring after repair of a nerve may be minimal, and strangulation of the sutured nerve unlikely. When a wound has been closed, or when a scar has been replaced by skin transplant, the incision for the subsequent nerve repair should be placed along one edge of the graft, so that scar tissue in the region of the suture is not amalgamated with an overlying scar in the skin.

Learmonth ${ }^{60}$ has advised that when the main vessel of a limb is injured at the same time as a nerve to that limb, it is wise to perform a preganglionic sympathectomy before the downgrowth of axons reaches the digits, to prevent the reimposition of a degree of vaso-constrictor tone on the digital vessels, and progressive circulatory inadequacy.

\section{Non-operative Mcasures}

Management of Denervated Extremities before Operation and during the Post-operative Period.This treatment involves the use of splints and other methods of immobilisation, massage, exercises, baths, electrical treatment, and occupational therapy.

It was remarkable, during the recent war, how much less were contractures and other deformities in denervated limbs which had not been immobilised than in those which had been carefully splinted. Nevertheless, certain splints are desirable. Splints should prevent the over-stretching of paralysed muscles, but should permit the free movement of the unaffected muscles. The aim of a splint should be to approximate the point of origin of the paralysed muscle to the point of its insertion, 49 and to avoid stretching by gravity or by unparalysed antagonists. Splinting should not be regarded as synonymous with immobilisation; the limb should not be immobilised and all joints must be allowed as full movement as is consistent with the relaxation of paralysed muscle. Splints must not press on anaesthetic skin or interfere with the circulation of an extremity whose circulation is in any case impeded, and they should be capable of being worn during occupational therapy and even at work. Useful splints of many varieties have been devised for the prevention of flexion deformity of the ring and little fingers in ulnar palsy, and for the prevention of over-stretching of the extensors by gravity in radial palsy, but in other situations splints are rarely necessary. Even the splints for these two deformities should be of a spring type, permitting full movement of all the antagonist muscles and of all the joints of the digit. Voluntary exercises have a high value, and should aim at exercising antagonist muscles and preventing the development of trick movements. They should be used too, but not to the point of fatigue, for recovering muscles.

Re-education of muscle should begin as soon as voluntary movement is recovered; a faradic response should not be awaited, for voluntary movement may precede it by weeks or months. The movement of a joint through its whole normal range will not usually over-stretch any paralysed muscles. Before exercises are begun, the limb should always be warmed for at least an hour; the exercise of the muscles of a cold limb has little advantage.

Massage is valuable, as also are baths in wax and in water, for the maintenance of nutrition in the limbs and for the correction of deformities if these are already present, but flaccid muscle is very vulnerable, and must not, in massage, be compressed against bone. As Mennell $7^{\circ}$ has observed, the ability of a masseur to treat nerve injuries can be measured by the change in technique when he passes from the normal to the flaccid part of the limb.

Electrical treatment is probably beneficial also, ${ }^{8}$ A galvanic current should be employed until the faradic response returns.4 Muscle atrophies even though electrical treatment be carried out, but the weight lost by a paralysed muscle is less if electrical treatment is maintained than if it is omitted. $3^{8}$ 
Fischer ${ }^{28}$ showed that muscle stimulated clectrically for twenty minutes a day undergoes a striking increase of weight compared with its resting fellow of the opposite side, and Gutmann and Guttmann $3^{6}$ demonstrated that while electrotherapy does not prevent atrophy during the first two weeks, it reduces the degree of later atrophy, and accelerates the return of function. Jackson and Seddon 57 showed also that electrical treatment does not prevent early wasting, but reduces the amount of that wasting, and they claimed, too, that galvanism arrests atrophy at about one hundred days after injury, whereas if galvanism is omitted atrophy continues for four hundred days. Galvanism does not restore the volume of muscle already lost, and it should therefore be started early.

\section{Operative technique}

The patient's position should be carefully arranged for operation, and a suitable anaesthetic chosen. In most cases, a general anaesthetic is employed. The only advantage conferred by local anaesthesia is the permission it affords for electrical stimulation of sensory fibres, but there is relatively little value in information so obtained (see above).

A long incision should be employed, placed usually in the line of the nerve. If a plastic operation has been done previously to provide skin replacement of a scar, the incision should circumscribe the transplanted skin.63 Care should be taken in approaching the nerve to effect complete haemostasis, but to avoid injury to any collateral channels, particularly if the main vessel of the limb has been simultaneously damaged. The nerve trunk or the ends of the divided nerve are identified and exposed, and the nerve is followed proximally and distally for a considerable distance, care being taken to preserve the origins of branches; the order in which branches leave the parent trunk, and even the actual level at which they arise, are fairly constant. The nerve can now be inspected, and, if it is undivided, surface petechiae, scarring, and congestion are noted. Careful palpation is performed for the detection of any local hardness or thickening, of a lateral neuroma, of alteration in texture, and of the presence of intraneural foreign bodies. If undivided or partly divided, the nerve is then tested directly by faradic current. Both the proximal and distal segments are tested, and the voltage employed must be graduated to avoid spread of current to neighbouring nerves, particularly when the nerve studied lies close to the point of separation of two main divisions, as in the case of the popliteal nerves below the bifurcation of the sciatic. During electrical testing, the nerve may conveniently be suspended on narrow tapes. The decision is then made whether to be content with the neurolysis which has already been performed, § or whether to proceed to excision and suture. 3 There is no difficulty in the choice of operation $\stackrel{\mathbb{Q}}{\varrho}$ when the nerve is completely divided. When the $\stackrel{c}{c}$ nerve is partly divided, it may be possible to $\vec{\Rightarrow}$ separate the divided from the undivided part and $\stackrel{5}{\rightarrow}$ to perform a partial suture. This is particularly $\bar{c}$ convenient when one or other of the popliteal $\underline{\underline{\sigma}}$ divisions is divided within the sciatic sheath, but $\frac{\bar{c}}{\vec{D}}$ the same technique may be applied to almost any $\mathbb{\complement}$ nerve which is the seat of partial neurotmesis. ڤ Should it be decided to perform partial suture, the $\vec{\theta}$ presence of undivided fibres in the scar of the apparently divided part of the nerve may be $\vec{\omega}$ detected directly by faradism.

When the continuity of a nerve is not completely interrupted, the decision whether to resect or not 3 . may be exceedingly difficult. If loss of function is $\mathrm{N}_{\mathrm{N}}$ complete, if a reaction of degeneration is present, $\dot{\sim}$ and if there is a palpable thickening and hardness $\rightarrow$ at the site of the lesion to suggest substantial intra- N neural fibrosis, resection is usually desirable. If o

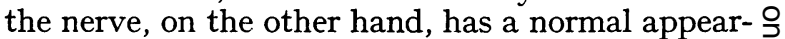
ance and feel, it should be left undisturbed even though loss of function is complete and R.D. $\mathbb{D}$ present. Lipchina ${ }^{66}$ and other Russian authors advise resection for localised intrafascicular haema- $\frac{\mathbb{D}}{3}$ toma-formation and oedema, even though the perineurium is intact and soft, but in most Britis centres the practice in early exploration has be $\overrightarrow{0}$ to avoid resection of a nerve unless it presen some local thickening and hardness. At earfy operation, if a faradic response cannot be elicited, hardness to touch is the most reliable criterion of the need for resection.

In the case of a complete division, the neuroma $\stackrel{\circ}{\mathbb{2}}$ of the proximal segment and glioma of the distal $\stackrel{\Omega}{\rightrightarrows}$ are excised by division of normal nerve. Each윽 bulb in turn is incised in successive incomplete slices, from its tip toward normal nerve, and the first slice which shows normal nerve bundles in the transected trunk is made complete, and that level $\frac{0}{3}$ is the point of excision of the bulb. It is particularly important to have well-defined funiculi 3 . obvious in the transected distal segment; the growing axons penetrate scarring in the proximal $\frac{}{3}$ stump more readily than they enter a scarred distal stump. During the process of successive slicing of the bulb and final section of the nerve, the nerve? and bulb may conveniently be laid on a straight metalspatula, around which moist gauze is wrapped. $N$ The best instrument for section is a Gillette razor blade carried on an artery forceps.2o The final section of the nerve should be directly transverse $\omega$ across it. In this way, two clean nerve ends are obtained for suture. The neuroma and glioma are preserved for histological examination; the experienced neuro-pathologist, estimating the state of ${ }^{-}$ 


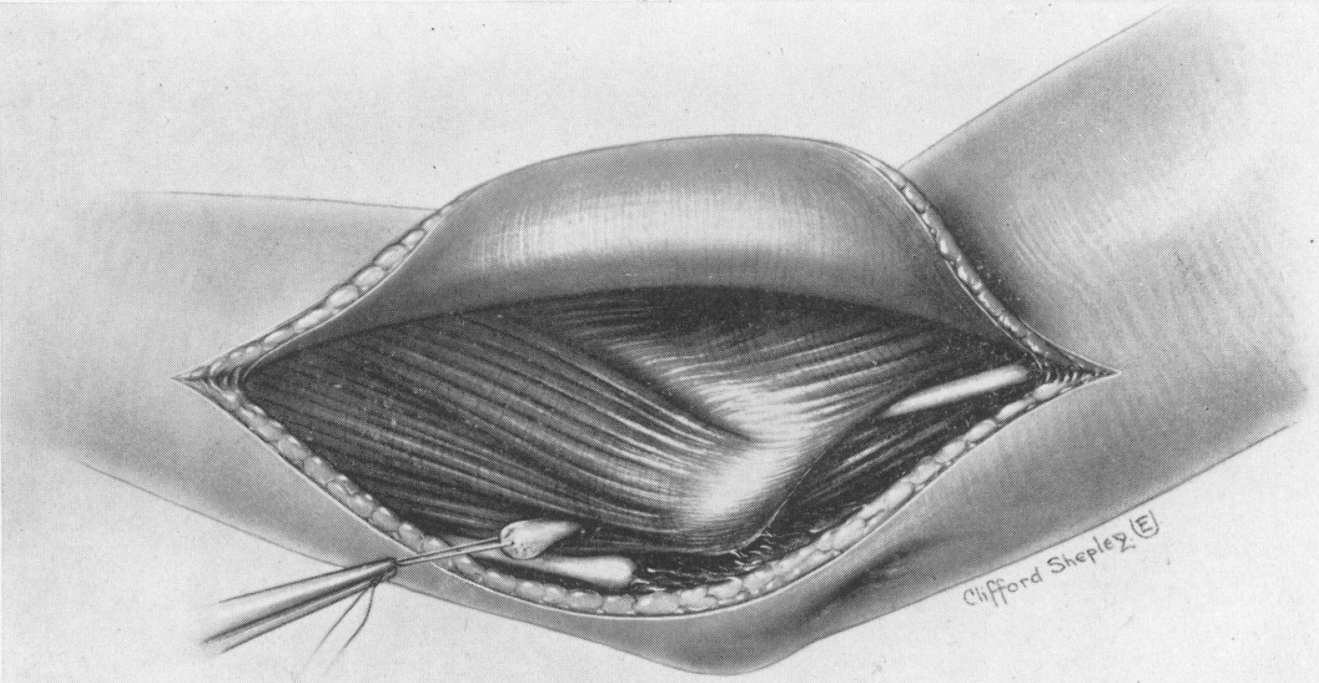

FIG. 9.-Repair of ulnar nerve at elbow. Neuroma drawn through tunnel deep to flexors near origin.

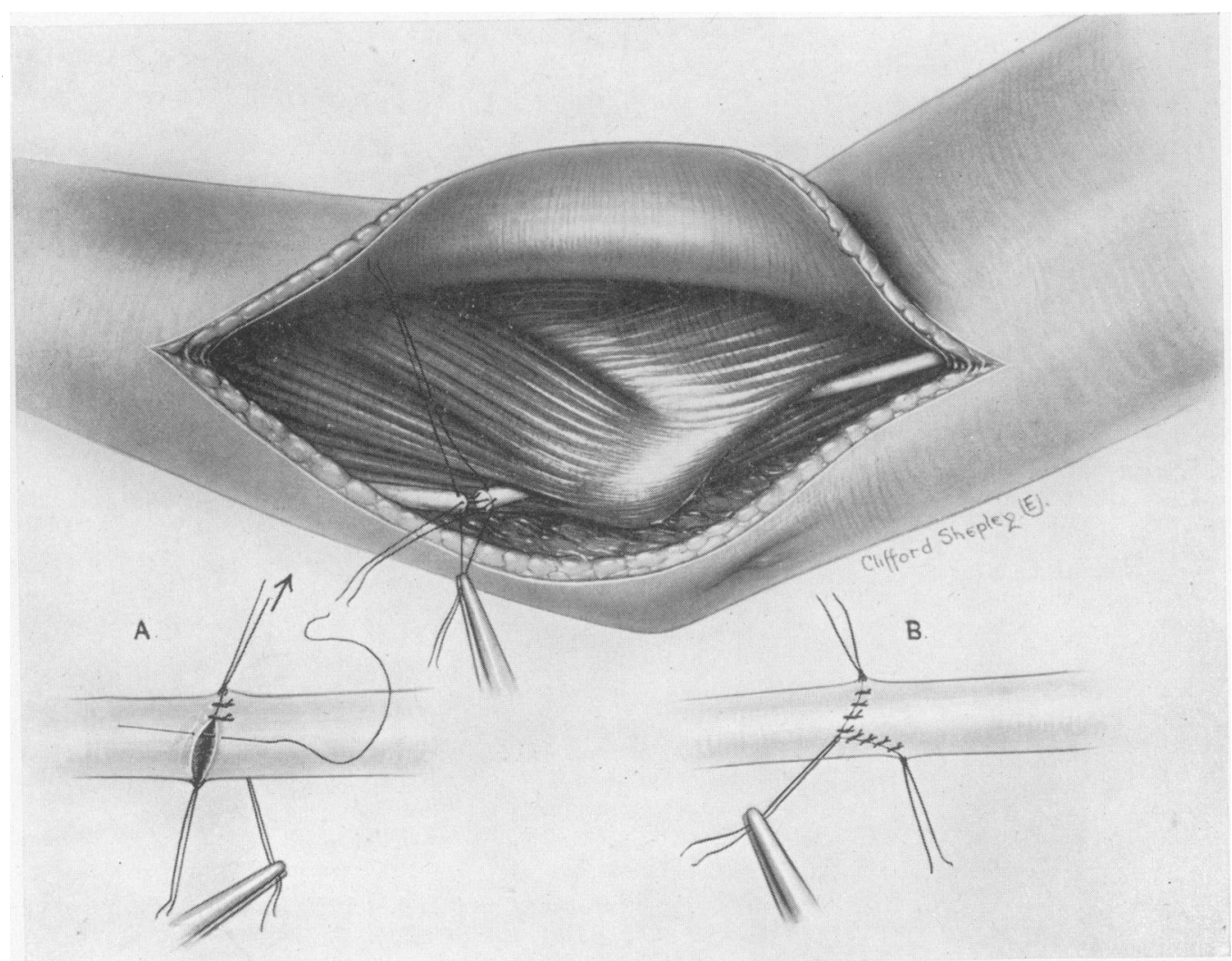

FIG. Io.--Repair of ulnar nerve at elbow. Suture completed. (A) Three tension sutures in place; insertion of anterior row of sutures. (B) The same; two rows completed. 


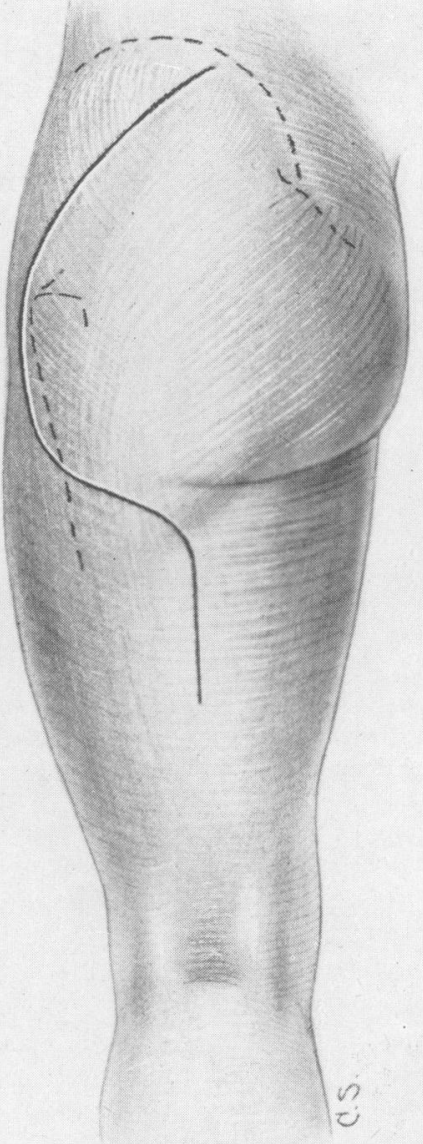

FIG. II.-Repair of high sciatic lesion. Question-mark incision.

(Reproduced by kind permission of "Surgery, Gynecology and Obstetrics.")

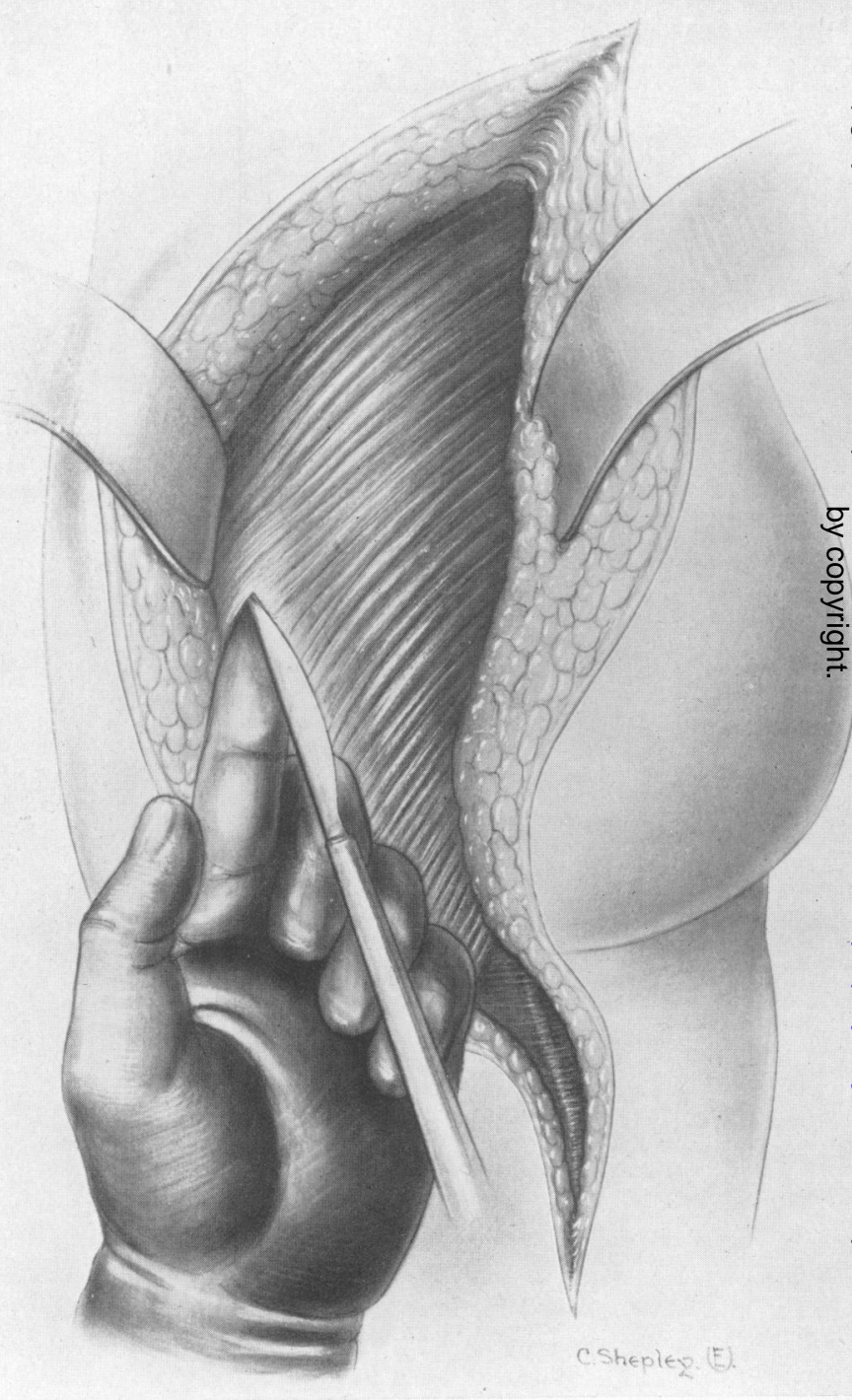

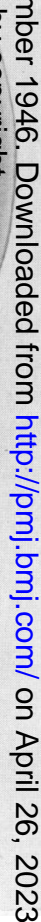

FIG. 12.--Repair of high sciatic lesion. Division of insertion oर gluteus maximus. (Reproduced by kind permission of "Surgery, Gynecology and Obstetrics." 
the divided ends of the nerve from the histological appearance of the extremities of the intervening segment, and observing the degree of intraneural fibrosis and the state of axons and Schwann elements, can hazard a valuable prognosis of the degree of recovery to be expected. When the ends have finally been prepared for suture the gap between them is carefully measured and recorded.

Two or three stay sutures are inserted axially through the clean nerve-ends, and are drawn tight together, and tied (Fig. IOA). They may conveniently be of silk. As they are tightened, neighbouring joints are placed in that extreme position which gives greatest relaxation to the nerve. The anastomosis then proceeds. Guttmann 43 has shown experimentally that of the available material for suture, human hair and white silk produce least reaction, but it is probable that the type of suture material used is not of very great moment, provided the suture is fine, unabsorbable, and carried on an eyeless needle of the same diameter as the thread. In nerves such as the radial which seem to lend themselves to successful suture, the suture is successful whatever material is used; it seems likely, therefore, that in other nerves, want of success is due more to the nature of the nerve than to the qualities of the suture material. The standard black silk atraumatic arterial suture now obtainable is perhaps most commonly used. Tantalum wire (0.003 inch) carried on an atraumatic needle is equally suitable for suture of nerve, but its only advantage is that disruption at the suture line can be recognised radiologically after operation. ${ }^{106}$ Young and Medawar ${ }^{10} 3^{\circ}$ introduced a form of sutureless anastomosis in experimental animals, and this was later used clinically by Seddon and Medawar 95 in man, and Michael and Abbott7' have reported favourably on human fibrinogen glue. In the method of Young and Medawar, the nerve-ends, having been approximated, are surrounded by a mixture of plasma and tissue extract which clots to a firm jelly and binds the nerve ends together. The plasma is freely permeable to growing axons, and remains long enough to give firm union between the divided ends before its final dissolution, which is complete. This form of anastomosis, fibrin suture, cannot be employed if there is any tension between the nerve ends, but it is useful in certain situations, such as the hand and fingers, where suture is not applicable.132 Tarlov and his fellow-workersiro, mi have devised a rubber mould which is used to surround the anastomosis with plasma clot, and to compress the clot while it sets.

In most operative situations, anastomosis is made by suture. The stay sutures having been tied the divided ends are approximated by interrupted stitches, which pierce perineurium only.7
The stitches are inserted at intervals of approximately $2 \mathrm{~mm}$. The stay sutures can be employed to rotate the anastomosis until it is circumferentially complete (Fig. IOB). On completion of the sutures, the anastomosis is gently rolled between thumb and forefinger, to return to the nerve its normal cylindrical contour.

If difficulty is found in approximating the divided ends of the nerve, various manœuvres are available to give relaxation. The nerve may be followed and dissected free proximally and distally for many inches. When approximation is attempted, branches arising from the proximal or distal segment may be found to be so taut that they prevent full relaxation. These branches usually retain their separate identity within the nerve sheath for a substantial distance above their apparent point of origin, and if they are stretched gently away from the nerve they may be freed by division of the sheath proximally with scissors; the funiculus to coraco-brachialis in the musculocutaneous nerve, that to flexor carpi ulnaris in the ulnar, and that to gastrocnemius and the posterior part of soleus in the medial popliteal retain their identity for particularly long distances within their parent trunks.

In some situations, additional length may be obtained by transplantation. This is particularly so in the case of the ulnar nerve, whose proximal segment may be freed above a division of the nerve in the forearm, or whose distal segment may be freed after division of the nerve in the upper arm by anterior transposition of the nerve at the elbow. In most cases, however, the operator is dependent upon a combination of the position of the limb and mobilisation of the nerve.

In performing anastomosis, a mild tension at the line of suture is said to be an advantage, tending to produce correct orientation of axon tips opposite appropriate Schwann tubes. ${ }^{129}$ Considerable tension, however, may prevent regeneration, $5^{\mathrm{I}}$ and the stretched nerve may, after operation, be transformed to a ribbon of connective tissue. 52 The biological limit of stretching is less than the anatomical limit52; a stretch of Io per cent of the mobilised length of a nerve may be applied without damage, but a 30 per cent stretch may be harmful even when done in stages.90 The operator is constantly faced with the temptation to overstretch. Spurlingro5 reported that although an insurmountable gap prevented suture in only $I$ per cent of approximately I,500 divided nerves explored in American centres in this country between D Day and VE Day, 4 per cent of the anastomoses were shown later to have separated.

When the gap between the nerves is too great to permit of repair by anastomosis without tension, the question arises whether a graft is likely to be 
successful. It may be said, initially but conclusively, that preserved grafts, hetero-grafts (from another species); and homo-grafts (from other individuals of the same species) have in no single instance been found to allow regeneration in man.4, $\mathrm{I}_{32}$ Fresh hetero-grafts induce a severe reaction and undergo none of the degenerative changes necessary for axon penetration. ${ }^{133}$ The alcohol-preserved and formol-fixed rat spinal cord of Gosset and Bertrand 33 is attacked by giant-cells and destroyed. Fresh homo-graft (in rabbit) may offer a basis for recovery, 9,133 but frequently provokes a lymphocytic reaction, which is only slightly lessened by previous saline storage. 39 The alcohol-fixed transplant of Nageotte73 is removed by microphages. Klemme59 has employed cadaver homo-grafts in man, but his results are not fully documented. The only peripheral nerve graft which has been used successfully in man is the auto-graft, the same individual serving as donor and recipient, and it has been shown ${ }^{126}$ that new fibres grow through an auto-graft hardly more slowly than through a peripheral stump. In some situations, auto-grafts have proved highly successful, notably in the repair of the facial nerve within the facial canal; in developing this operation Duel and Ballance,5, 24 adopted for transplant the predegenerated nerve recommended on theoretical grounds by $\mathrm{Cajal}^{17}$ in I928; Sanders and Young91 have shown, however, that the only measurable advantage conferred by predegeneration is an increased toughness of the perineurium to the tension of sutures.

For a graft to be successful, it must not only be obtained from the same patient, it must also be of the same diameter or a little larger than the nerve for whose repair it is employed. The technique of grafting entails the interposition of the graft and a double suture proximally and distally. No practical advantage has been reported from the secondary excision and suture of the distal anastomosis after an interval as suggested by Davis and Cleveland 19 and by Dogliotti. ${ }^{23}$

The ideal type of nerve graft is found in double lesions of the ulnar nerve when that nerve has been transected both above and below the elbow; its intervening segment, being from the same patient and of precisely the same size, may be transplanted to the front of the elbow as a perfect free graft. Nerve grafts may be used, in combination with a plasma technique, to replace wide gaps in digital nerves. In nerve injury of both plantar nerves, the lateral plantar may be employed to replace a defect of the medial plantar, and in a double injury of the popliteal nerves it is legitimate to sacrifice a part of a widely divided lateral popliteal, where paralysis can be compensated by orthopaedic operation, to replace a defect in the medial popliteal, whose regeneration is so much more important. To repair a long defect in a large nerve a "cable graft" may be employed-several pieces of $\stackrel{\mathbb{Q}}{\varrho}$ a small nerve inlaid in parallel, so that their sum-c. mated cross-sections exceed the sectional area of the injured nerve.

Another expedient in the repair of large gaps is? the method of bulb suture. If it is decided, before trimming of the divided nerve ends, that the gap is $\frac{\bar{\rho}}{\vec{\sigma}}$ too large to close immediately by suture, the bulbs $\mathbb{\Omega}$ may be left in place and sutured to each other as a® temporary measure, excision and formal anastomosis being postponed until a later date. Here. again, it is doubtful what success may be expected, $\vec{\omega}$ for it seems probable that nerve tissue is noto capable even of slow stretching with safety. When a gap is too large for anastomosis, at a site which 3 . does not lend itself to nerve graft, all idea of suturej is usually abandoned, and reliance is placed on later $\tilde{N}$ orthopaedic measures for the recovery of motor $\rightarrow$ function in the limb.

When anastomosis is complete, its distance from $N$ the nearest bony landmark is measured and re-음 corded, for precision in calculating the distancewhich the growing axons must cover, and assistance $\mathbb{\infty}$ in predicting the date of functional recovery. The nerve should be placed in a comfortable bed, where $\frac{\mathbb{D}}{3}$ it is unlikely to be strangulated in scar tissue. Theo safest bed for an anastomosed nerve is in the plaße between two muscles, and, failing that, within tre $\overrightarrow{0}$ substance of a muscle. If possible, the ner should not be left in a subcutaneous position; tho applies particularly to the ulnar nerve at the elbow, to the median nerve at the wrist, and to the sciatic nerve in the thigh. A nerve lying between muscles or within a muscle need not be surrounded, $\stackrel{\circ}{\mathrm{D}}$ as has been suggested, by tantalum foili 05 or by an arterial tube ${ }^{128}$ or by cargile membrane. In no을 circumstances should a nerve be swathed in fascia lata after anastomosis. ${ }^{16}$

While suture of the wound is completed, the limb is continuously held in that position which윽 affords maximum relaxation to the repaired nerve, and a well-padded plaster cast is applied to retain 3 that position after operation. The plaster cast remains, usually, for $4-6$ weeks after operation, $\frac{}{3}$ and thereafter the limb may be gradually brought into the position of comfort and of optimum function.

After operation, splinting, massage, electrical treatment, baths, occupational therapy, and psychological encouragement are continued; a close $N$ watch is kept for the signs of recovery, which are carefully documented, and gentle exercises areㅇ begun as soon as voluntary power is noticed inc each successive recovering muscle.

\section{Prognosis}

The prognosis in a case of nerve injury is never. 
final throughout the whole course of treatment; prognosis is a dynamic development approaching, but never quite attaining, perfect accuracy as new facts become available with the passage of time. An accurate early prognosis is possible if a nerve is seen intact at the initial débridement of an open wound; a less accurate prognosis is possible if it is seen divided at that time. Return of function after a week or two, too early to be explained by regeneration, is characteristic of neurapraxia and relatively rapid and full recovery can be predicted. The reaction of degeneration, the onset of fibrillation in the electro-myograph, and increasing steepness of the strength-duration curve exclude neurapraxia and promise disability for some months.

At the time of definitive operation, prognosis is narrowed within more exact limits. If the nerve, though showing signs of degeneration, is found intact and free from thickening (axonotmesis) it can confidently be predicted that full function will be recovered, and a fairly accurate date for the return of function in each denervated muscle may be calculated from the known rules which govern the rate of regeneration. If, on the other hand, it is found divided, and is repaired by suture, a fairly exact prognosis can be estimated from: (I) the period from time of injury to time of operation, (2) the degree of atrophy and the presence or absence of stiffness and contracture, (3) the magnitude of the gap, (4) the degree of tension after suture, (5) the neuropathologist's report upon the state of intraneural architecture at the lines of section of proximal and distal stumps, (6) the level of the anastomosis, (7) the habitual characteristic behaviour of the particular nerve injured, (8) the circulatory efficiency of the denervated area, and (9) the age, re-educability, and willingness of the patient.

Later still, the strength-duration curve, the myograph, and sometimes muscle biopsy may be employed to check, correct, or even alter, a previous prognosis.

\section{Results of Treatment}

A final evaluation of recovery should be delayed until at least $2 \frac{1}{2}$ or 3 years after injury. ${ }^{8}$ Recovery is never complete after suture, but after axonotmesis and neurapraxia a complete return of function may be hoped for. Foerster $3^{\circ}$ reported I,320 complete and 660 partial motor recoveries, all spontaneous, in a series of 3,099 peripheral nerve injuries sustained in the first world war.

\section{Individual Nerves}

No complete consideration of the individual nerves is attempted; notes are given which may be helpfully additional to a working knowledge of the applied anatomy of those nerves which are more commonly damaged.

I. Cranial Nerves. Facial nerve injuries have been extensively studied by Duel and Ballance,5, $24 \stackrel{\varrho}{\mathrm{C}}$ and their established technique for the replacement of lost facial nerve by degenerated laterals cutaneous nerve of the thigh is well established ando most successful. Starr has recorded a successfulo two-stage suture of the facial nerve trunk within $\frac{\bar{m}}{\frac{1}{6}}$ the parotid gland after a gunshot injury. The only $\mathbb{\varnothing}$ other cerebral nerves whose extracranial injuries@ have been reported are the last four cranial nerves, $\rightarrow$ which may be injured together in wounds of the. neck with associated damage to the carotid vessels $\vec{\omega}$ and sometimes to the sympathetic chain. The symptoms such an injury produces are groupedo together in the "traumatic syndrome of Villaret 3 . and Vernet." Ir 8, Ir 9 The facial nerve is sometimesin concomitantly damaged. Injuries of these nerves ${ }_{i}^{N}$ have not been successfully treated by operation, $\rightarrow$ T but all the symptoms of nerve damage tend toin improve except the vagus and accessory paralysis. N There is usually a persistent abductor paralysis of으 the larynx, and some dysphagia.

The accessory nerve may be injured alone in the $\overline{8}$ neck, with paralysis of the trapezius, and with oro without sternomastoid palsy. This nerve does not $\stackrel{\mathbb{\Phi}}{3}$ lend itself to repair.

2. Brachial plexus injuries comprise a subject $t \&$ vast and complicated for full description here. $\mathbb{t} \overrightarrow{0}$ may be said simply that injury of the cords and बेf their branches may be undertaken with high hope of success, injury of the trunks should be attempted but success is unlikely, and in injury of the roots operation is hopeless. $6,44,5^{8}$

3. The long thoracic nerve is affected in less than $\frac{2}{\circ}$ one half of I per cent of war wounds; serratus $\stackrel{2}{\rightarrow}$ anterior paralysis has followed excision of breast $\overline{0}$ and incisions for axillary abscess. Spontaneous 3 paralysis of the serratus anterior muscle may develop from traumatic long thoracic neuritis as an occupational lesion of such workers as plasterers, 윽 who hold the arms above the head for long periods, and in porters who carry on their shoulders weights with sharp edges; in these the lower fibres of trapezius sometimes suffer too for an unexplained $\frac{0}{3}$ reason. A similar palsy in swimmers may be caused from friction by the scalenus medius as the $\frac{}{工}$ arm is carried forwards in the breast-stroke, and $\rightarrow$ perhaps this explains the occupational form of the palsy.

The long thoracic nerve cannot well be repaired unless it is seen divided accidentally in the course 0 of an operation. The winging of the scapula $\omega$ which results from the nerve palsy can be corrected only by the orthopaedic surgeon.

4. The axillary nerve is seldom injured alone $\frac{\mathbb{D}}{}$ in gunshot wounds, though it may be damaged $\stackrel{?}{+}$ 
in "crutch palsy"; deltoid paralysis (with loss of external rotations too) is the most prominent sign in upper brachial plexus forms of birth palsy. Treatment lies in the field of the orthopaedic surgeon.

5. Paralysis of the musculocutaneous nerve gives. relatively little disability. Flexion of the elbow can be performed efficiently if part of brachialis has a radial supply; even if this is lacking, good flexion of the pronated forearm is possible by brachio-radialis; the supinated forearm can be flexed, if biceps and brachialis are out, only if the flexors of the forearm are exceptionally able substitutes.

6. The medial cutaneous nerve of the forearm supplies an area of skin whose anaesthesia is not of great importance, but if it is divided together with median or ulnar its repair may be attempted when the larger nerve is explored. This nerve is temptingly convenient for service as a graft for median or ulnar, but its small calibre makes it quite ineffective for this purpose.

7. The radial nerve. This nerve may be injured in the arm by a fracture of the humerus, by tourniquet or plaster pressure, or by pressure on the edge of an operating table. It may be damaged at the elbow in fracture of the neck or head of the radius or in dislocation of the radius. It may be damaged at any level in an open wound. The posterior interosseous nerve may suffer an irritation neuritis just at its entry into the supinator muscle, perhaps from repeated pronation and supination, as in Guillain and Courtellemont's orchestra conductor, 35 perhaps because of its close relation here to the bicipito-radial and interosseous bursae; ${ }^{125}$ the thumb extensors suffer oftenest, but all wrist and finger extensors may be affected.34, 6r If the nerve is injured below the middle of the arm, not only triceps but brachio-radialis escapes, and sometimes the branches to extensor carpi radialis and even those to the finger extensors leave the parent trunk at a surprisingly high level. In injuries above the elbow, supination of the flexed forearm is lost, but biceps continues to supinate the fully-extended forearm. The sensory paralysis varies with the level of the injury. In injuries high in the arm, the lateral cutaneous nerve of the arm is involved, and there is sensory loss also from the radial side of the thumb over the dorsum of the second and third metacarpals, but even in high injuries free anastomosis with musculo-cutaneous and medial cutaneous nerves may prevent any sensory loss at all. In lower injuries there is never much sensory loss, for the musculo-cutaneous and lateral cutaneous nerves of the forearm virtually replace the sensory function of the radial.

When testing for extensor paralysis, each individual extensor tendon should be tested, with the metacarpo-phalangeal joints in the flexed position, so that the interossei, which can extend the extended fingers, are thrown out of action. Extension of the thumb may be mimicked by abductor pollicis brevis, and sometimes, especially if the extensor tendons have been shortened by splinting, the patient can extend the fingers by flexing the wrist, just as he can dorsiflex the wrist by flexing the fingers (Fig. I). The radial nerve recovers after suture better than any other nerve in the body, perhaps because it is so purely motor that crossing of axons is of no importance. After a suture in the arm, recovery may be expected in nine to twelve months.

8. The median nerve may be injured, not only by open wounds, but by fracture of the lower humerus, or even of both bones of the forearm; in the latter fracture its volar interosseous branch may suffer alone. The median nerve may be injured also in dislocation of the lunate bone, and it may follow a Colles's fracture. It may be compressed by bandages or splints, or by a tourniquet, and an occupational paralysis of the median may occur in the users of trowels, scrubbing brushes and planes. An ischaemic paralysis may occur from injury to the volar interosseous artery, and damage to this vessel should be avoided in repairing a median lesion.99 In paralysis of the median nerve, the only digits which lose all flexion are the thumb and index. Pronation is feeble, and completed only by the weight of the forearm. In high lesions, the wrist flexes to the ulnar side. The paralyses of abductor, opponens, and half of flexor? brevis pollicis are difficult to test individually,, 08 but the first metacarpal is usually prominent, and it is difficult to raise the thumb forwards at right angles to the plane of the palm (abductor), or to bring the thumb against resistance to touch the tip of the little finger (opponens). The former of these tests is the most specific test for a median motor lesion, 89 for the short abductor is the only thenar muscle invariably innervated by the median, $5^{\circ}$ but in its performance the muscle belly of abductor brevis should be palpated to see whether it contracts, for if opponens has a substantial ulnar innervation, it may, acting in concert with abductor longus, carry the thumb well forward from the plane of the palm. ${ }^{109}$. Tricks which may be acquired to cover a median paralysis are: flexion of the wrist by abductor pollicis longus (continuing even when median and ulnar nerves are both out), and unusually good flexion of the fingers by the ulnar part of profundus. ${ }^{89}$

The sensory area of the median nerve is also subject to considerable variation (Figs. 2, 3), but sensation to the tip of the index finger is exclusively median. The median nerve is said to be subject more commonly than other nerves to neuroma formation after suture, and a case is recorded in 


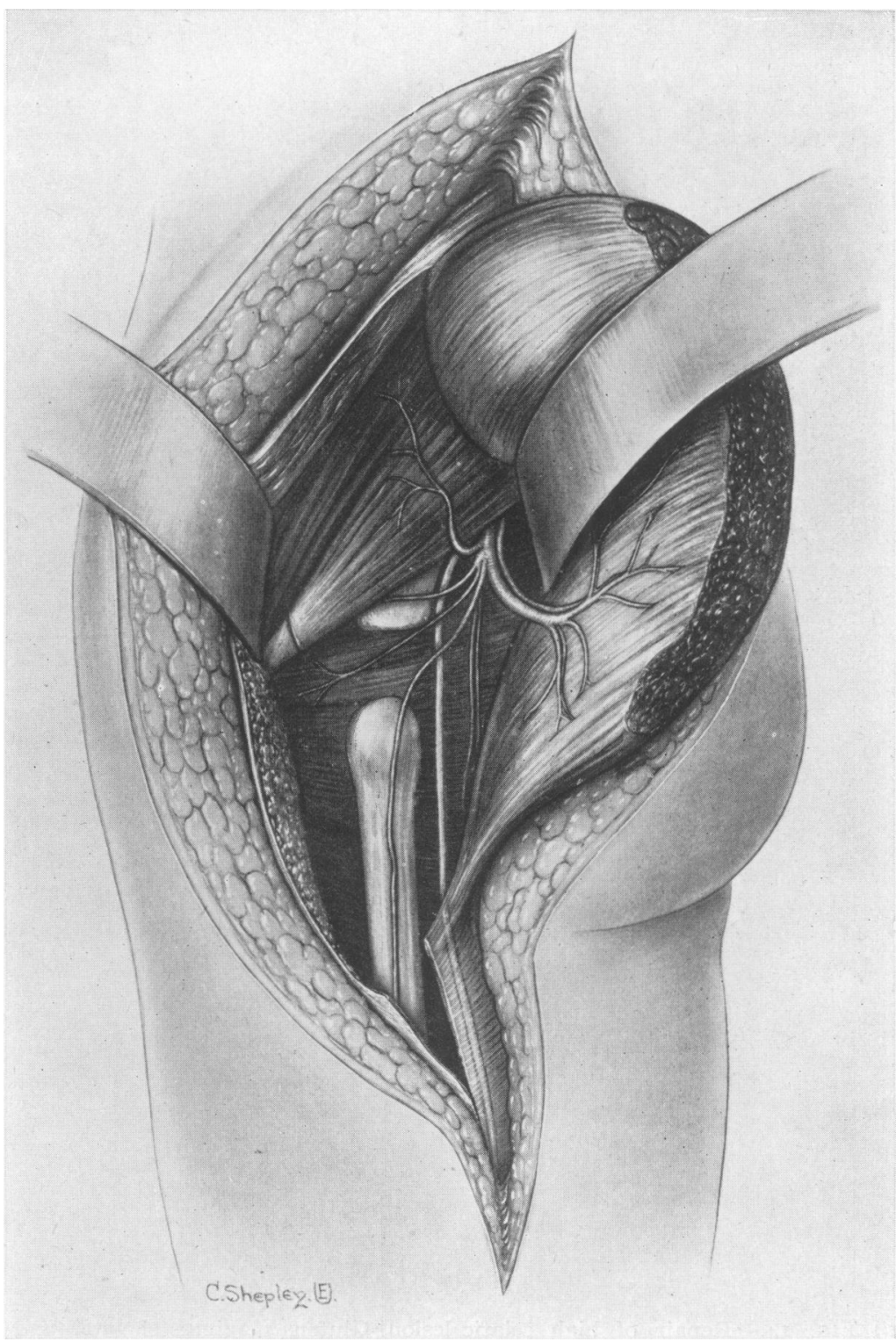

FIG. I3.-Repair of high sciatic lesion. Gluteus maximus elevated; line of incision of piriformis tendon.

(Reproduced by kind permission of "Surgery, Gynecology and Obstetrics.") 


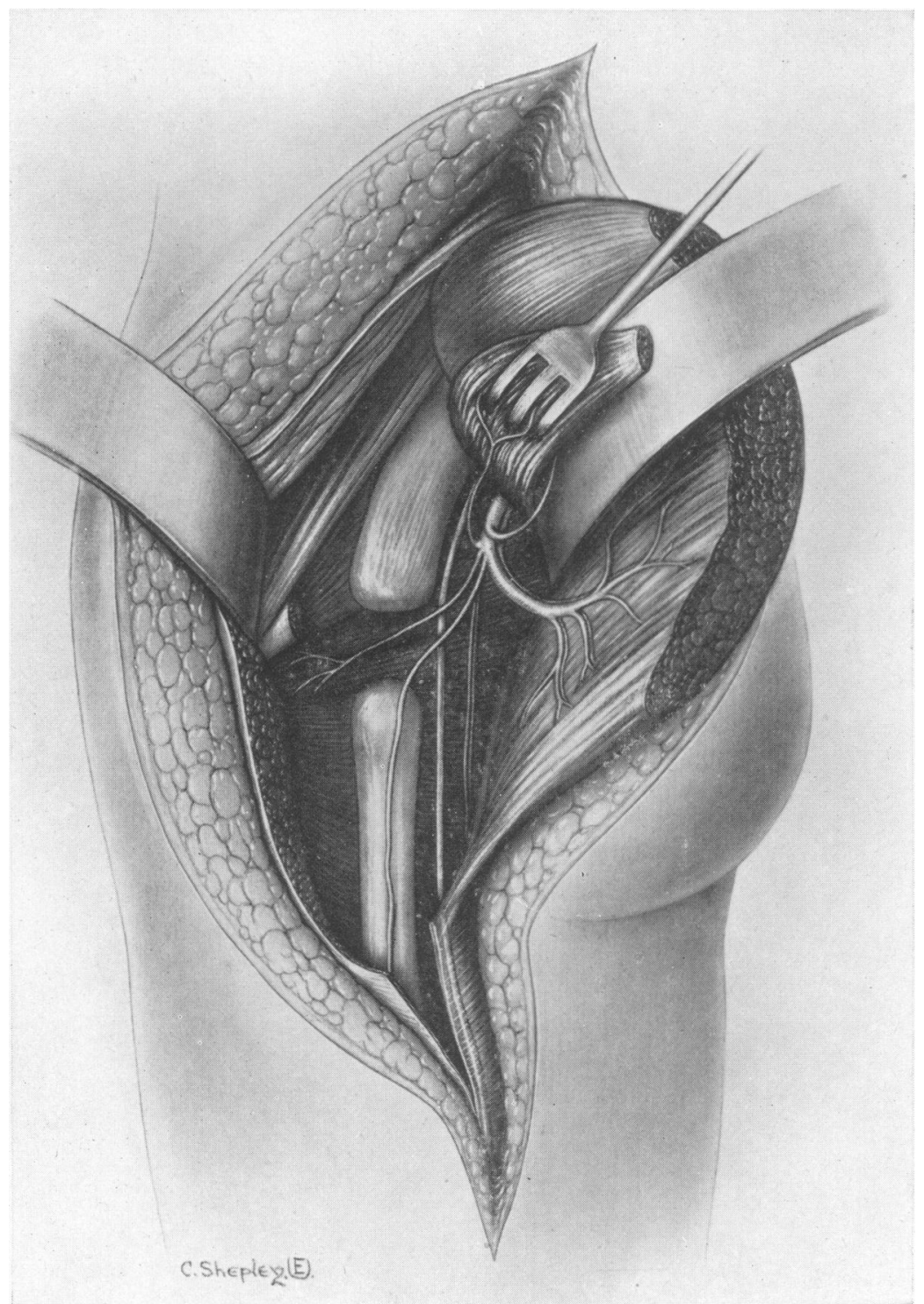

FIG. I4.-Repair of high sciatic lesion. Gluteus maximus elevated and piriformis divided. Note relaxation of branches of inferior gluteal vessels, and full exposure of proximal segment of nerves.

(Reproduced by kind permission of "Surgery, Gynecology and Obstetrics.") 
which such a neuroma developed spontaneously twelve years after operation. ${ }^{26}$ The maximum gap which can be closed successfully by suture is $7 \mathrm{~cm} .5 \mathrm{r}$ The chief disability in median paralysis is sensory and this is of importance in deciding operative treatment. Motor paralysis may be disregarded, provided some sensory recovery is obtained. The most serious part of the motor disability is the loss of opponens. ${ }^{67}$ Recovery, is rather more rapid, length for length, in the median nerve than in the ulnar. ${ }^{67}$ The median nerve, like the posterior tibial, is subject to hyper-excitability and causalgia after injury.

9. The ulnar nerve may be injured by wounds and by fractures in the region of the elbow, and it suffers, too, from tardy palsy if a valgus deformity, the result of a supracondylar fracture, produces irritation of the nerve behind the elbow. In contradistinction to division of the median nerve, division of the ulnar is important by reason of the muscular rather than of the sensory paralysis which it produces. The fine movements of the hand are lost, and hand function is seriously damaged. The loss of the inner half of flexor digitorum profundis is not of great moment; the important paralysis is the loss of the small muscles in the hand. The typical main-en-griffe produced by loss of the interossei and lumbricals (affecting the inner two fingers more than the outer, since the latter conserve a greater lumbrical action), gives extension at the metacarpal-phalangeal joints and flexion of the distal finger joints. The predominance of this deformity in annularis and minimus is lost to some extent if the lesion is above the ulnar contribution to profundus; hence, the higher the lesion the less the deformity. There is hollowing on the dorsum between the extensor tendons (from loss of the interosseous muscles) and the hypothenar eminence is flattened. There may be a noticeable flattening, too, on the dorsal aspect of the first metacarpal space, from loss of the first dorsal interosseous muscle. The belly of this muscle may be palpated when the index finger is abducted against resistance. The little finger, in ulnar paralysis, is held slightly abducted, and cannot be adducted against the ring finger. Weakness of the interossei can be determined by interlocking the patient's fingers with the examiner's, and the loss of grip between the fingers is obvious. The patient, too, is unable to grip a sheet of paper between the extended digits. Trick movements here are:

(I) Unusually effective flexion of the little finger by a wide median innervation of profundus,

(2) Abduction of the fingers by the long extensor tendons, and,

(3) Abduction of the fingers by the flexors of the fingers. ${ }^{89}$
There is surprisingly little disability often after an ulnar lesion if its muscular territory is small in extent.95 As in the case of median lesions, the procaine block method of Highet is invaluable for determining anomalies of distribution.

For the repair of injuries, the ulnar nerve offers a greater prospect of the relief of wide gaps than does any other nerve in the body, for it can readily be transplanted to the front of the elbow, and after such transplantation a gap of II $\mathrm{cm}$. can sometimes be closed without tension. In exposure of an injured ulnar nerve, a suitable incision (Learmonth ${ }^{62}$ ) is made along the line of the nerve (Fig. 6 ), which may be exposed first in the groove behind the internal condyle (Fig. 7). The nerve may then be followed upwards into the arm, and downwards into the forearm between the heads of flexor carpi ulnaris. It usually gives off two articular branches as it lies in the groove, and these may be sacrificed if transposition is required; indeed, transposition of a sutured ulnar nerve is always desirable, since it is less exposed to the risk of strangulation by scar tissue in the intermuscular plane in front of the elbow than in the bony canal behind it. In the distal part of the groove, usually, the upper branch to flexor carpi ulnaris leaves the main trunk, and it may sometimes have to be sacrificed to mobilise the nerve adequately upwards, though usually it may be liberated from the parent trunk for severalo centimetres above its apparent point of exit. The nerve can, however, be mobilised downwards as fato as its contribution to flexor digitorum profundus.? If the nerve has been divided above or below the level of the bony canal, it is unnecessary to detach completely the flexor origin from the medial epicondyle. A forceps is merely passed deep to it, and a cotton swab is withdrawn deep to the flexor origin (Fig. 8), to make a tunnel through which the ulnar segment of the divided nerve may be drawn by a stitch transfixing its bulb (Fig. 9). If the nerve division is precisely at the centre of the bony canal, the flexors must be detached, as they are detached in a transposition of the intact nerve. In its final anterior position, the nerve should lie in the same intermuscular plane as the median. Particular care is required to make sure that the medial intermuscular septum is divided down to the epicondylic ridge, and that the fascia of flexor carpi ulnaris is divided down to the ulna, as either of these two fascial bands may produce a postoperative irritation of the nerve trunk. Transposition of the ulnar nerve may permit the repair of a gap of the order of II cm.5I

I0. The sciatic nerve. The sciatic nerve may be damaged by open wounds, by prolonged pressure on the back of the thigh, by tourniquet constriction, or by the pressure of an aneurysm of the companion artery of sciatic nerve3r; injury has 
occurred also as a result of dislocation of the hip or repair of a congenital dislocation, pressure of the foetal head on the lumbo-sacral plexus, in parturition, and even an awkward jump or fall. In the sciatic palsy which has rarely followed a simple springing jump, intraneural bleeding from the companion artery of the sciatic nerve has been blamed.

For repair of the divided sciatic nerve, the patient lies prone with a pillow under the knee to extend the hip, and with the knees flexed. In the back of the thigh the nerve may be conveniently exposed by a median posterior incision, with avoidance of injury to the posterior cutaneous nerve. In the approach to a high lesion, a question-mark incision $47,7^{2}$ around the borders of the gluteus maximus muscle, with its vertical limb down the middle of the back of the thigh (Fig. II) allows the fascia lata and the insertion of gluteus maximus to be divided (Fig. I2) and permits that muscle to be thrown medially towards its origin, like a lid, to expose the sciatic nerve at the lower border of piriformis (Fig. I3). If, before gluteus maximus is so elevated, the tendon of the piriformis is divided, piriformis can be elevated together with gluteus maximus. 3 This relaxes the tension on the branches of the inferior gluteal veins, as they run forwards under the edge of piriformis, and lessens the risk that one of these may be torn from its parent trunk (Fig. I4). If a torn gluteal vessel retracts into the pelvis, it may be difficult to apply a haemostat safely to it. This form of exposure also permits a quite high suture of the sciatic nerve to be performed at the very point of its emergence from the pelvis. When the wound is closed, care must be taken to avoid including the posterior cutaneous nerve in a stitch; this can be ensured by overlapping the edges of the deep fascia (Fig. I5).

The sciatic nerve, more perhaps than any other, lends itself to a partial repair, for the medial and lateral poplital branches are separate within the main trunk usually for a considerable distance, and can be treated as separate nerves. The maximum gap in a sciatic nerve which can be repaired without tension is in the neighbourhood of $8 \mathrm{~cm}$., but a much smaller gap may be impossible to repair if the lesion is a high one. If the gap in the sciatic nerve is too wide to suture without dangerous tension, it is legitimate to use a segment of the lateral popliteal nerve as a graft to bridge the defect in the medial popliteal. The muscular palsy which is the most serious disability of a lateral popliteal lesion can be corrected by orthopaedic measures, while the sensory paralysis of a medial popliteal lesion is a permanent and serious disability if not repaired. The position of the patient during the operation must be maintained for three weeks at least after suture of the sciatic nerve. This can conveniently be done by a complete hip spica, or the flexed knee, in a plaster extending from upper thigh to ankle, may be slung from a Balkan beam to maintain extension of the hip. The exaggerated position is tiresome for the patient, and is not always well borne.

II. The lateral popliteal nerve may be injured by open wounds, by fractures in the region of the neck of the fibula, by direct blows on the neck of the fibula, and by traction injuries. Platt 79 described originally the closed injury of the lateral popliteal nerve which occurs from a severe adduction strain on the knee with rupture of the fibular collateral ligament; sometimes the tendon of biceps too is ruptured, or the head of the fibula avulsed; the iliotibial tract and the cruciate ligaments may also suffer damage. In some cases, the nerve is actually ruptured, while in some the continuity is preserved. The injury was further studied by Highet and Holmes $^{5}$; Leclerq ${ }^{6}$ had previously described cases of the injury, but had not recognised the mechanism by which it was produced. In one of Platt's patients, the nerve suffered neurapraxia, which recovered completely in four weeks, but in all other cases there was a complete lesion with extensive damage, and spontaneous recovery did not occur in them even when nerve fibres were subsequently shown to have penetrated the scar. The lateral popliteal nerve may proceed to satisfactory recover after repair in the thigh or in the popliteal fossa, and in this area gaps of as much as $9 \mathrm{~cm}$. have beep successfully sutured, but adequate recovery is के exceptional if the nerve is sutured beyond the point of its departure from the fossa; it is usually a saving of time to the patient to proceed immediately to orthopaedic correction of "dropfoot" deformity.

I2. The medial popliteal and posterior tibial nerves should be repaired by suture if possible, or, if not, by a nerve graft, for any sacrifice is justified to return sensation in the sole of the foot. The motor disability after a medial popliteal lesion is not great; paralysis of the short muscles of the foot results in a clawing deformity which can be, to some extent, corrected by a pad under the sole. The maximum gap which can be corrected by suture in the case of this nerve is of the order of $6 \mathrm{~cm} .5^{\mathrm{r}}$

\section{BIBLIOGRAPHY}

(For illustrations of the methods of testing the voluntary power of various muscles, reference should be made to the pamphlet "Aids to the Investigation of Peripheral Nerve Injuries" (69), and to Haymaker and Woodhall's "Peripheral Nerve Injuries" (46). To avoid unmanageable length, reference has been made mainly to papers published during the $\mathrm{N}$ past seven years.)

I. ABERCROMBIE, M., and JOHNSON, M. L., "Outwandering of Cells N in Tissue Cultures of Nerves undergoing Wallerian Degeneration," J. Exper. Biol., 1942, 19, 266-283.

2. ADRIAN, E. D., "Interpretation of the Electro-myogram," Lancet, I 925, 1, I 229-I233 and I 282-I 286.

. AIRD, I., "The Surgical Approach to High Lesions of the Sciatic Nerve,"'Surg. Gynec. Obst. (In Press).

4. ANGLESIO, B., and BRUNI, A., "Sugli esiti di Lesioni Traumatiche $\frac{}{(\top)}$ dei Nervi Periferici," Berichte über den VIII Kongress für Unfallmedizin und Berufskrankheiten, Frankfurt, 1938, 2, 440-448. 
Fig. I5.--Repair of high sciatic lesion. Closure of musculo-fascial layer. Note overlapping of fascia lata in thigh so that posterior cutaneous nerve, in one edge of fascia, escapes injury.

(Reproduced by kind permission of "Surgery, Gynecology and Obstetrics.") 
5. BALlANCE, C., and DUEL, A. B. "Operative Treatment of Facial Palsy by Introduction of Nerve Grafts into Fallopian Canal and by other Intra-temporal Methods," Arch. Otolaryngol., 1932, 15, 1-70. 6. BANKART, B., "Discussion on Injuries to the Brachial Plexus," Proc. Roy. Soc. Med., 1930, 23, 1286.

7. BAUDENS, J. B. L., "Clinique des Plaies d'Armes à Feu," 8vo, pp. 6 Io and xv; Paris; 1836 , J. B. Baillière.

8. BAUWENS, P., "Electro-Diagnosis and Electro-therapy in Peripheral Nerve Lesions," Proc. Roy. Soc. Med., I94 I, 34, 459-468.

9. BENTLEY, F. H., and HILL, M., "The Possibilities of Nerve Grafting," Brit. Med. J., 1940, 2, 252-353.

Io. BISHOP, G. H., "Responses to Electrical Stimulation of Single Sensory Units of Skin," J. Neurophysiol., 1943, 6, 361-382.

I1. BLACKWOOD, W., "A Pathologist Looks at Ischaemia," Edin. Med. $J$, r944, 51, I 1 I-r 43

12. BOWDEN, R. E. M., "Changes in Human Voluntary Muscle in Denervation and Re-innervation," Brit. Med. J., I945, 2, 487-488.

13. BOWDEN, R. E. M., and GUTMANN, E., "Denervation and Reinnervation of Human Voluntary Muscle," Brain, I944, 67, 2733 I 3 .

I4. BOWDEN, R. E. M., and GUTMANN, E., "Clinical Value of Muscle Biopsies," Lancet, 1945, 2, 768-771.

15. BUNNELL, S., and BOYES, J. H., "Nerve Grafts," Amer. J. Surg.,

I6. CAIRNS, H., and YOUNG, J. Z., "Treatment of Gunshot Wounds of Peripherai Nerves," Lancet, 1940, 2, 1 $23-126$.

17. y CAJAL, R., "Degeneration and Regeneration of Nervous System," Translated and Edited by Raoul M. May, 2 vol., pp 769 and $\mathbf{x x}$, viii. $8 \mathrm{vo}$, London, 1928 , Humphrey Milford.

18. COLEMAN, C. C., "Surgical Treatment of Peripheral Nerve Injuries," Surg. Gynec. Obstet., 1944, 78, I $13-124$.

19. DAVIS, L., and CLEVELAND, D. A., "Experimental Studies in Nerve Transplants," Ann. Surg., I934, 99, $271-283$.

20. DEJARDIN, L., and JONCKHEERE, F., "La Chirurgie reparatrice des nerfs peripheriques." Berichte über den VIII Internationalen Kongress für Unfallmedizin und Berufskrankheiten, Frankfurt, I $938,2,36$ I-40I.

21. DENNY-BROWN, D. E., and BRENNER, C., "Lesion in Peripheral Nerve Resulting from Compression by Spring Clip," Arch. Neurol. Psychiat., 1944, 52, I-19.

22. DENNY-BROWN, D. E., and PENNYBACKER, J. B., "Fibrillation and Fasciculation in Voluntary Muscle." Brain, 1938, 61, 3 II -334

23. DOGLIOTTI, A. M., "I Processi riparativi delle Lesioni dei Nervi Periferici (excluso il simpatico)," Berichte über den VIII Kongress für Unfallmedizin und Berufskrankheiten, Frankfurt, 1938, 2, 402418.

24. DUEL, A. B., "History and Development of Surgical Treatment of Facial Palsy," Surg. Gynec. Obstet., 1933, 56, 382-390.

25. ECCLES, J.C.," Changes in Muscle Produced by Nerve Degeneration," Med. J., A ustral., 104I, 1, 573-575.

26. EHALT, W., "Behandlungsergebnisse von Verletzungen peripheren Nerven," Berichte über den VIII Kongress für Unfallmedizin und Berufskrankheiten, Frankfurt, I 938 , 2, 4I9-440.

27. ELKIN, D. C., and WOODHALL, B., "Combined Vascular and

Nerve Injuries of Warfare," Ann. Surg., I944, 119, 4 I I-43I.
28. FISCHER, E.," The Effect of Faradic and Galvanic Stimulation upon the Course of Atrophy in Denervated Skeletal Muscles," Amer. J. Physiol., I939, 127, 605-619.

29. FOERSTER, O., "The Dermatomes in Man," Brain, 1933, 56, I-39.

3o. FOERSTER, O., "Degeneration und Regeneration des Peripheren Nervensystems," Deutsch. Zeitschr. $f$. Nervenheilk., x930, 115, $248-314$

3I. FOERSTER, O., "Die Verletzungen der Peripheren Nerven," Berichte iiber den VIII International Kongress für Unfallmedizin und Berufskrankheiten, Frankfurt, 1938, 2, 325-354.

32. FULTON, J. F., "Physiology of the Nervous System." 2nd. Ed. Oxford Univ. Press, London, 1943, pp. 6I 4 with I I 2 illustrations.

33. GOSSET, A., and BERTRAND, I., "La moelle épinière, utilisée comme greffon hétéroplastique dans les blessures des nerfs périphériques," J. Chirurg. (Par.), 1938, 5, 481-505.

34. GRIGORESCO, D., and IORDANESCO, G., "Un cas rare de Paralysie partielle du Nerf radial," Rev. Neurol., I93 I, 2, 102-104.

35. GUILLAIN, G., and COURTELLEMONT, "L'Action du muscle court supinateur dans la paralysie du nerf radial," Presse Mél., $1905,1,50-52$.

36. GUTMANN, E., and GUTTMANN, L., "Effect of Electrotherapy on denervated Muscles in Rabbits," Lancet, I942, 1, I69-1 70.

37. GUTMANN, E., GUTTMANN, L., MEDAWAR,P.B., and YOUNG, J. Z., "The Rate of Regeneration of Nerve," J. Exper. Biol., I942, 19, I $4-44$.

38. GUTMANN, E., "Factors affecting Recovery of Motor Function after Nerve Lesions," J. Neurol. Psychiat., I 942, 5, 8 I-95.

39. GUTMANN, E., and SANDERS, F. K., "Functional Recovery following Nerve Grafts and other Types of Nerve Bridge," Brain, I942, 65, 373-408.

40. GUTMANN, E., and SANDERS, F. K., "Recovery of Fibre Numbers and Diameters in Regeneration of Peripheral Nerves," J. Physiol., I $943,101,489-5$ I 8 .

4I. GUTMANN, E., and GUTTMANN, L., "Effect of Galvanic Exercise on Denervated and Re-innervated Muscles of Rabbit," Journ. Neurol. and Neurosurg. Psych., 1944, 7, 7-17.

42. GUTTMANN, L.; "Topographic Studies of Disturbances of Sweat Secretion after complete Lesions of Peripheral Nerves," J. Neurol. Psychiat., 1940, 3, 197-210.
43. GUTTMANN, L., "Experimental Study on Nerve Suture with Various Suture Materials," Brit. J. Surg., 1943, 30, 370-375

44. HARRIS, W., "Discussion on Injuries to the Brachial Plexus," Proc. Roy. Soc. Med., 1930, 23, $1282-1285$.

45. HARVEY, A. M., and KUFFLER, S. W., "Motor Nerve Function with Lesions of the Peripheral Nerves. A Quantitative Study," Arch. Neurol. Psychiat., 1944, 52, 317-322.

46. HAYMAKER, W., and WOODHALL B." "Peripheral Nerve Injuries," W. B. Saunders and Coy., Philadelphia, 1945, 8vo, 227 \& xiv, 225 Illustrations.

47. HENRY, A. K., "Extensile Exposure applied to Limb Surgery," 8 vo, 180 \& viii, E. \& S. Livingstone, Edinburgh, I.945.

48. HIGHET, W. B., "Procaine Nerve Block in Investigation of Peripheral Nerve Injuries," J. Neurol. Psychiat., I 942, 5, Ior-1 16.

49. HIGHET, W. B., "Splintage of Peripheral Nerve Injuries," Lancet, $1942,1,555-558$.

50. HIGHET, W. B., "Innervation and Function of Thenar Muscles," Lancet, $1943,1,227-230$.

51. HIGHET, W. B., and HOLMES, W., "Traction Injuries to Lateral Popliteal Nerve and Traction Injuries to Peripheral Nerves after Suture," Brit. J. Surg., 1943, 30, $212-233$.

52. HIGHET, W. B., and SANDERS, F. K "Effects of Stretching Nerves after Suture," Ibid., 1943, 30, 355-369.

53. HOFMANN, E., "Zur Indikationsstellung operativer Eingriffe nach Schussverletzungen peripherer Nerven," Deutsch. Militärart. $1943,8,217-223$.

54. HOLMES, W., and MEDAWAR, P. B., "Local Application of Sulphonamide to Peripheral Nerves," Lancet, I942, 2, 334-335.

55. HOLMES, W., and YOUNG, J. Z., "Nerve Regeneration after Immediate and Delayed Suture," J.'A nat., 1942, 77, 63-96.

56. HYMAN, I., and BESWICK, W. F., "Measurement of Skin Resistance in Peripheral Nerve Injuries," War Medicine, Chicago, 1945, $8,258-260$.

57. JACKSON, E. C. S., and SEDDON, H. J., "Influence on Galvanic Stimulation on Muscle Atrophy resulting from Denervation," Brit. $M e d . J$., 1945, 2, 485-486.

58. JEFFERSON, G., "Discussion on Injuries to the Brachial Plexus," Proc. Roy. Soc. Med., I930, 23, 1 $282-1285$.

59. KLEMME, R. M., WOOLSEY, R. D., and de REZENDE, N. T. "Autopsy Nerve Grafts in Peripheral Nerve Surgery. Clinical Application," J. Amer. Med. A ssoc., 1943, 123, 393-396.

6o. LEARMONTH, J. R., "Personal Experience of Exploration and Re-exploration of Injured Nerves," Proc. Roy. Soc. Med., 1944, 37,

6r. LEARMONTH, J. R., and WOLTMANN, H. W., "Progressive Paralysis of the Nervus Interosseus Dorsalis," Brain, 1934, 57 25-3I.

Nerve," Surg. Gynec. Obstet., 1942, 75, 792-793. "Certain Plastik
63. LEARMONTH, J. R., and WALLACE, A. B., ", Problems in the Surgery of Peripheral Nerves," Ibid., 1943, 76 106-109.

64. LECLERCQ, J., and MULLER, M., "Lésions du nerf sciatique poplité externe par traumatismes fermés," Berichte über den VIII Kongress für Unfallmedizin und Berusfkrankheiten, Frankfurt, I938, 2, 402-4 18 .

65. LEWIN, W.," "Pressure Palsy in the Paralysed Limb," Lancet, I943, 2, $756-758$

66. LIPCHINA, L. P., "Intra-neural Processes after Trauma to Peripheral Nerves without Damage to the Epineurium," Problemy Nyerokhirurgiy, Moscow, I943, pp. 19-28.

67. MARBLE, H. C., HAMLIN, E., and WATKINS, A. L., "Regeneration in the Ulnar, Median, and Radial Nerves," Amer. J. Surg., 1942, 55, 274-294.

68. M.R.C. Nerve Injuries Committee, "Note on the Assessment of Recovery in Peripheral Nerve Injuries" (W. B. HIGHET).

69. M.R.C. Nerve Injuries Committee, "Aids to the Investigation of Peripheral Nerve Injuries," I943. (Prepared by Staff of Department of Surgery, University of Edinburgh.) pp. 48 , with 78 illustrations.

7o. MENNELL, J., "Massage, Movements, and Exercises in the Treatment of Nerve Suture and Repair," Brit. J. Phys. Med., I942, 5 , $40-47$.

7r. MICHAEL, P., and ABBOTT, W., "The Use of Human Fibrinogen in Reconstructive Surgery," J. Amer. Med. Assoc., 1943, 123, 279.

72. NAFFZIGER, H. C., and NORCROSS, N. C., "Surgical Approach to Lesions of Upper Sciatic Nerve and Posterior Aspect of Hip Joint," Surgery, 1942, 12, 929-932.

73. NAGEOTTE, J., "Sur la greffe des tissus morts," Compt. rend. Soc. de Biol., Par., $1917,53,459-470$.

74. NATHAN, P. W., and RENNIE, A. M., "Value of Tinel's Sign," Lancet, 1946, 1,6ro-6ri.

75. NORCROSS, N. C." "Early Repair of Neural Wounds with Penicillin Therapy," Arch. Surg., I 945, 50, 67-68.

76. PAR KES, A. R., "Traumatic Ischaemia of Peripheral Nerves with some Observations on Volkmann's Ischaemic Contracture," Brit. J. Surg., I945, 32, 403-414.

77. PHILIPPIDES, D., "Die Prüfung der Vasomotor funktion bei

Peripheren Nerven Läsionen," Der Chirurg., I942, 14, $385-389$.
78. PLATT, H.," War Injuries of Peripheral Nerves," Post-Graduate Med. J., I940, 16, 256-259.

79. PLATT, H., "Traction Lesions of the External Popliteal Nerve," Lancet, 1940, 2, 6 I $2-614$.

8o. POLLOCK, L. J., "Overlap of So-called Protopathic Sensibility as Seen in Peripheral Nerve Lesions," Arch. Neurol. Psychiat., 1919, 2, 667-700. 
81. POLLOCK, L. J., "Nerve Overlap as related to the relatively early Rebirth of Pain Sense following Injury to the Peripheral Nerves," J. Compar. Neurol., 1920, 32, 357-378.

82. POLLOCK, L. J., and DAVIS, L., "Peripheral Nerve Injuries," N.Y., I933, Hoeber, pp. 678 (3I2 illustrations).

83. POLLOCK, L. J., "Evaluation of Incapacity Produced by Injuries of the Peripheral Nerves," Surg. Gynec. Obstet., I94I, 73, $462-47 \mathrm{I}$.

84. RICHARDS, R. L., "Vasomotor Disturbances in the Hand after Injuries of Peripheral Nerves," Edin. Med. J., I943, 50, 449-468.

5. RICHARDS, R. L., "The Assessment of Sensory Denervation after Injuries of Peripheral Nerves," Ibid., 1946, 53, 110.

86. RICHTER, C. P., and KATZ, D. T., "Peripheral Nerve Injuries determined by Electrical Skin Resistance Method; Ulnar Nerve," J. Amer. Med. Assoc., 1943; 122, 648-65 I.

87. RITCHIE, A. E., "The Electrical Diagnosis of Peripheral Nerve Injury," Brain, 1944, 67, 314-430.

88. ROTTGEN, "Zur Frage der Kontrastdarstellung der Verletzungen Peripherer Nerven," Der Nervenarzt, 1943, 16, 244-54.

89. RUSSELL, W. R., and HARRINGTON, A. B., "Early Diagnosis of Peripheral Nerve Injuries in Battle Casualties," Brit. Med. J.,

9o. SANDERS, E. K., "The Repair of Large Gaps in the Peripheral Nerves," Brain, 1942, 65, 281-337.

9r. SANDERS, F. K., and YOUNG, J. Z., "The Degeneration and Reinnervation of Grafted Nerves," $J$. A nat., 1942, 76, 143-166.

92. SCHAFER, E. SHARPEY, "Effects of Denervation of Cutaneous

93. SCHAFER, E. S., "Exp. Physiol., 1928, 19, 85-107. Brain, I927, 50, 538-547.

94. SEDDON, H. J., "Classification of Nerve Injuries," Brit. Med. J., I942, 2, $237-239$.

95. SEDDON, H. J., and MEDAWAR, P. B., "Fibrin Suture of Human Nerves," Lancet, I942, 2, 87-88.

96. SEDDON, H. J., YOUNG, J. Z., and HOLMES, W. "Histological Condition of Nerve Autograft in Man," Brit. J. Surg., I942, 29, 378-384.

97. SEDDON, H. J., "Three Types of Nerve Injury," Brain, I943, 66, 237-288

98. SEDDON, H. J., MEDAWAR, P. B., and SMITH, H., "Rate of Regeneration of Peripheral Nerves in Man," J. Physiol., I943, 102, I9I-2I 5 .

99. SEDDON, H. J., and HOLMES, W., "Ischaemic Damage in the Peripheral Stump of a Divided Nerve," Brit. J. Surg., 1945, 32,

roo. SHAPIRO, K. M., "The Significance of Chronaximetry in the Diagnosis of Gunshot Wounds of Peripheral Nerves," Problemy Nyerokhirurgiy, Moscow, 1943, pp. 28-37.

Ior. SILVERMAN, J. J., and POWELL, V. E., "A Simple Technic for Outlining the Sweat Pattern,"War Medicine, Chicago, 1945, 7,

ro2. SOLANDT, D. Y., and MAGLADERY, J. W., "Relation of Atrophy to Fibrillation in Denervated Muscle," Brain, 1940, 63, 255-263.

I03. SPEIDEL, C. C., "Studies of Living Nerves, III. Phenomena of Nerve Irritation and Recovery, Degeneration and Repair," $J$. Comp. Neurol., 1935, 61, I-80.

I04. SPERRY, R. W., "Functional Results of Crossing Sensory Nerves in the Rat," Ibid., 1943, 78, 59-9o.

105. SPURLING,'R. G., "Peripheral Nerve Injuries in European Theatre of Operations. Management with special Reference to Early Nerve Surgery," J. Amer. Med. Assoc., I945, 129, Ior I-1014.

106. SPURLING, R. G., and WOODHALL, B., "Experiences with Early Nerve Surgery in Peripheral Nerve Injuries," Ann. Surg., 1946,

107. SULLIVAN, W. E., and MORTENSEN, O. A., "Visualisation of Movement of Brominised Oil along Peripheral Nerves," Anat. Rec., 1934, 39, 493-501.
I08. SUNDERLAND, S., "The Significance of Hypothenar Elevation in Movement of Opposition of the Thumb," A ustral. \& New Zeal. J. م)

Surg., I944, 13, I57-I59.
rog. SUNDERLAND, S., "Voluntary Movements and the Deceptive Action of Muscles in Peripheral Nerve Lesions," Ibid., I944, 13, $\vec{D}$ $160-184$.

r ro. TARLOV, I. M., and BEN JAMIN, B., "Plasma Clot and Silk Suturec of Nerves; Experimental Study of Comparative Tissue Reaction,"

Surg. Gynec. Obstet., I943, 76, 366-374.
III. TARLOV, I. M., DENSLOW, C., SWARZ, S., and PINELES, D.,心 "Plasma Clot Suture of Nerves; Experimental Technique," I943, 47, $44-58$

I I2. TINEL, J., "Le Signe du fourmillement dans les lésions des nerfs $\frac{\sigma}{\sigma}$ périphériques," Presse Méd., I9I 5, 23, 385-386.

Ir3. TINEL, J., "Nerve Wounds; Symptomatology of Peripheral Nerve $\overline{\bar{\omega}}$ Lesions Caused by War Wounds." Translated by F. Rothwell. $\vec{\nabla}$ Rev. and edited by C. A. Joll. London, Baillière, Tindall \& Cox, 르

Ir4. TOONNIS, W., and GOTZE, W., "Zur operativen Behandlung der Schussverletzungen der peripheren Nerven und ihre Erfol gsaus sichten," Deutsch. Militarartz, 1942, 7, 245-253.

I I5. TÖNNIS, W., "Wann sollen die Schussverletzungen der peripheren Nerven operiert werden?" Ibid., r944, 9, r75-r77.

I 6 . TROTTER, W., and DAVIES, H. M., "Experimental Studies in the $\vec{\omega}$ Innervation of the Skin," $J$. Physiol., r 1909, 38, 134-246.

II7. TROTTER, W., and DAVIES, H. M., "The 'Peculiarities of Sensi bility found in Cutaneous Areas supplied byRegenerating Nerves,"ס Journ. für Psychol. und Neurol., I913, 20, 102-1 50.

I I. VERNET, M., "Syndrome du Tron déchiré postérieur (Paralysie des nerfs glosso-pharyngien-pneumogastrique-spinal), Rev. Neurol. iv Paris, I918, 25, II7-148.

II9. VILLARET, M., "Le syndrome de l'espace retro-parotidien pos- iv térieur," Presse Mdd., I917, 23, 430-431. G

120. WALSHE, E. M. R., "Anatomy and Physiology of Cutaneous $\rightarrow$ Sensibility," Brain, 1942, 65, 48-112.

I2I. WEDDELL, G., and GLEES, P., "The Early Stages in the De-N generation of Cutaneous Nerve Fibres," J. Anat., r94 I, 76, 65-93. G 122. WEDDELL, G., "Axon Regeneration in Cutaneous Nerve Plexuses," 음

123. WEDDELL, G., GUTTMANN, L., and GUTMANN, E., "The Local Extension of Nerve Fibres into Denervated Areas of Skin,"

124. WEDDELLl. Psychiat., I941, 4, 206-225.
Neurol, FEINSTEIN, B., PATTLE, R. C., "The Clinical $\frac{\mathbb{D}}{O}$ Application of Electromyography," Lancet, 1943, 1, 236-239.

125. WEINBERGER, L. M., "Non-Traumatic Paralysis of Dorsal Inter- (D) osseous Nerve," Surg. Gynec. Obstet., I939, 69, 358-363.

126. WEISS, P., "Experimental Innervation of Muscles by Central Ents of Afferent Nerves with functional Tests," J. Comp. Neurod, 느

127. WEISS, P., "Reunion of Stumps of Small Nerves by Tubulation instead of Suture," Science, I94 I, 93, 67-68.

128. WEISS, P., "Nerve Regeneration" in the Rat following Tubude. Splicing of Severed Nerves," Arch. Surg., 'I943, 26, 525-517.

129. WEISS, P., and TAYLOR, A. C., "Histomechanical Ánalysis 花 Nerve Reunion in Rat after Tubular Splicing," Ibid., I943,47, ᄋ

rзo. YOUNG, J. Z., and MEDAWAR, P. B., "Fibrin Suture of Peripheral Nerves; Measurement of the Rate of Regeneration," Lancet, 1940, 2, I 26-1 28.

I3r. YOUNG, J. Z., HOLMES, W., and SANDERS, F. K., "Nerve $\frac{2}{(D)}$ Regeneration; Importance of the Peripheral Stump and the \& Value of Nerve Grafts," Lancet, 1940, 2, 128-130.

132. YOUNG, J. Z., "The Functional Repair of Nervous Tissue," Physiol. $\overline{\bar{O}}$ Rev., I942, 22, 3 18-374. (See this for physiology of repair.)

133. YOUNG, J.'Z., "The Basic Sciences in Surgery," Edin. Med. J., $1946,52,262-276$. 